\title{
Land-based mitigation in climate stabilization
}

\author{
Steven K. Rose a,*, Helal Ahammad ${ }^{\text {b }}$, Bas Eickhout ${ }^{\text {c }}$, Brian Fisher ${ }^{\text {d }}$, Atsushi Kurosawa ${ }^{\text {, }}$, Shilpa Rao ${ }^{\mathrm{f}}$, \\ Keywan Riahi ${ }^{\mathrm{f}}$, Detlef P. van Vuuren ${ }^{\mathrm{c}, \mathrm{g}}$ \\ a Electric Power Research Institute (EPRI), 2000 L Street NW, Suite 805, Washington, DC, 20036, USA \\ ${ }^{\mathrm{b}}$ Australian Bureau of Agricultural and Resource Economics and Sciences (ABARES), Canberra, Australia \\ c PBL Netherlands Environmental Assessment Agency, Bilthoven, The Netherlands \\ d BAEconomics Pty Ltd, Kingston, Australia \\ e The Institute of Applied Energy (IAE), Tokyo, Japan \\ ${ }^{\mathrm{f}}$ International Institute for Applied Systems Analysis (IIASA), Laxenburg, Austria \\ ${ }^{g}$ Utrecht University, Utrecht, The Netherlands
}

\section{A R T I C L E I N F O}

\section{Article history:}

Received 12 November 2009

Received in revised form 6 June 2011

Accepted 12 June 2011

Available online 23 July 2011

\section{JEL classification:}

Q19

Q23

Q24

Q42

Q54

\section{Keywords:}

Climate change

Land use

Forestry

Agriculture

Bioenergy

Land economics

Greenhouse gas mitigation

Terrestrial sequestration

\begin{abstract}
A B S T R A C T
This paper evaluates the role of land in long-run climate stabilization mitigation scenarios. The details of land modeling for common stabilization policy scenarios are, for the first time, presented, contrasted, and assessed. While we find significant differences in approaches across modeling platforms, all the approaches conclude that land based mitigation - agriculture, forestry, and biomass liquid and solid energy substitutes - could be a steady and significant part of the cost-effective portfolio of mitigation strategies; thereby, reducing stabilization cost and increasing flexibility for achieving more aggressive climate targets. However, large fossil fuel emissions reductions are still required, and there are substantial uncertainties, with little agreement about abatement magnitudes. Across the scenarios, land mitigation options contribute approximately 100 to $340 \mathrm{GtC}$ equivalent abatement over the century, 15 to $40 \%$ of the total required for stabilization, with bioenergy providing up to $15 \%$ of total primary energy. Long-run land climate modeling is rapidly evolving with critical challenges to address. In characterizing current capability, this paper hopes to stimulate future research and the next generation of land modeling and provide a point of comparison for energy and climate policies considering bio-energy, reduced deforestation and degradation, and cost containment.
\end{abstract}

(c) 2011 Elsevier B.V. All rights reserved.

\section{Introduction}

Land's role in climate change and greenhouse gas (GHG) mitigation has received less attention than energy systems and is not well understood. However, land-use and land cover are crucial to climate stabilization. The future dynamics of land-use and land cover are shaped by market demands for land-based goods and services, climate and non-climate policies, and also regional climate and atmospheric feedbacks. Changes in land-use practices and technologies could also contribute significantly to minimizing the costs of climate policies and may be essential for very low long-run climate targets.

The lack of attention and understanding of land use in climate change is, in large part, because the explicit modeling of land-based

\footnotetext{
* Corresponding author. Tel.: +1202 2936183.

E-mail address: srose@epri.com (S.K. Rose).
}

climate change mitigation in global scenarios is relatively new and rapidly developing. It was only a few years ago that data and model development permitted modeling of mitigation portfolios that include terrestrial sequestration and multigas emission reduction land mitigation strategies (see Weyant et al., 2006). In addition to being scientifically important, keen international policy interest in costcontainment, developing country participation, bioenergy, and reduced deforestation and degradation, has given greater urgency to the need for evaluating and advancing climate land modeling. Even if land activities are not considered as mitigation alternatives by policy, land's dynamic atmospheric inputs role (emissions, sequestration, and albedo) is paramount, as is its susceptibility to changes in the atmospheric condition. Fig. 1 portrays the basic structural relationships between land-use and land cover and the climate and economic systems. Global land-use and land cover modeling is a vital and challenging frontier for energy and climate related modelingeconomic, integrated assessment, and earth systems. 


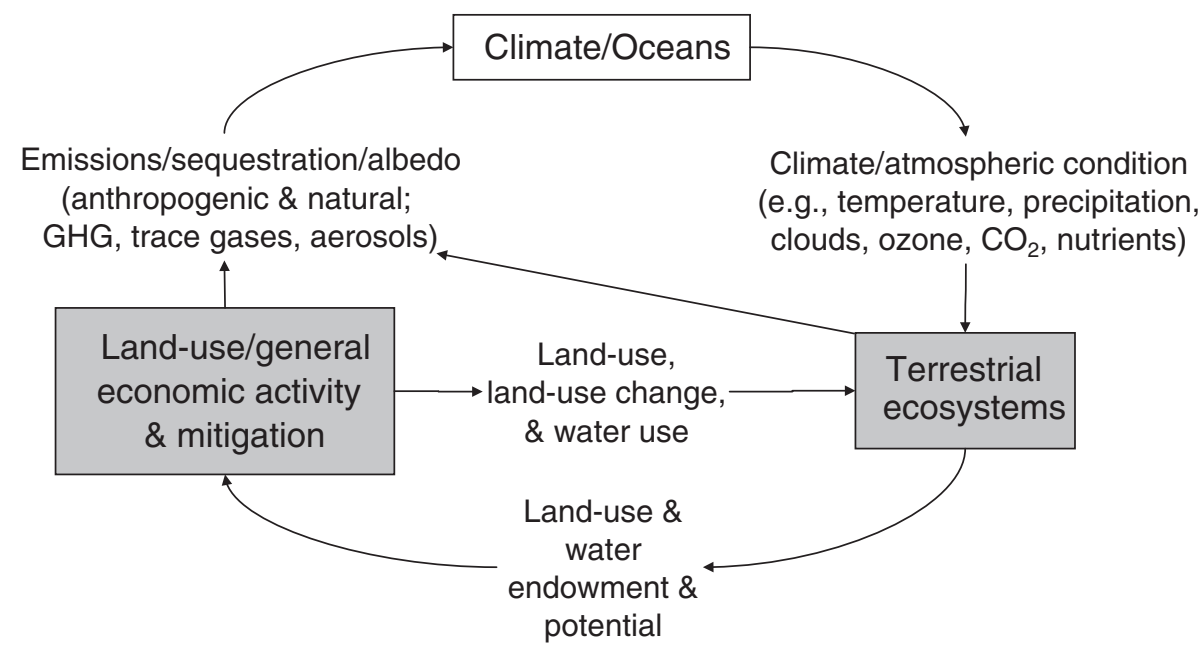

Fig. 1. Land in long-term climate modeling.

Integrated Assessment Models (IAMs) are increasingly modeling land-based mitigation, such as bioenergy fossil fuel substitutes and expanded forest land carbon, and their contributions to radiative forcing and climate change (Fig. 1). A few models also include climate feedbacks to managed land ecosystems. IAMs are used to explore the costs and benefits of very long-run policy-options for managing climate change. Model comparison studies (e.g., EMF-19; Weyant et al., 2006) have been an important part of model development, identifying robust conclusions, contributing to a better understanding of model and scientific uncertainties, and improving model quality. Unlike energy-related emission modeling however, a detailed direct comparison and evaluation of the integrated assessment land modeling work that has begun to emerge has not yet been made.

This paper is a first attempt to elucidate and assess the role of landbased mitigation in climate stabilization mitigation scenarios. In particular, this paper develops and evaluates, for the first time, the details of land modeling in common stabilization policy scenarios. These scenarios were selected on the basis of their explicit inclusion of land-based mitigation and their modeling of common climate stabilization targets. While each of the scenarios included land-based mitigation, land mitigation and modeling details were not the focus of those publications and were therefore not transparent, much less analyzed. With this paper, we have extracted and assembled detailed results and land modeling specifics in a comparative analysis of current land modeling. The approaches are all different with different strengths and weaknesses. As such, the paper does not set out to identify a preferred approach or set of results.

The paper aims to respond to a growing interest in understanding land's role in climate change mitigation-by the Intergovernmental Panel on Climate Change (IPCC), policy-makers considering long-term climate targets, domestic policy design of offset programs to potential emissions allowance trading schemes, future climate stabilization modeling, and a burgeoning global discussion on long-term mitigation potential of bioenergy and avoided deforestation. The paper provides a detailed characterization of current land modeling in stabilization scenarios. In doing so, it reveals robust conclusions across scenarios and highlights uncertainties, current capabilities and limitations, and critical model features and challenges. As such, the paper hopes to serve as a benchmark for modeling and policy insights, and as a guide for future model development and policy design. ${ }^{1}$

\footnotetext{
${ }^{1}$ There are substantial uncertainties in historic global land-use change emissions. For example, the IPCC reports that gross emissions from 1990s deforestation and other land-use change activities in the tropics ranged from 0.5 to $2.7 \mathrm{GtC}$-equivalent/yr, with a central estimate of $1.6 \mathrm{GtC}$-equivalent/yr (IPCC, 2007). Note that Houghton (2008) lowered the 1990s land-use change emissions estimates from the $2.2 \mathrm{GtC} / \mathrm{yr}$ reported in Houghton (2003) due to downward revision of estimated tropical deforestation.
}

The next section provides a background discussion-briefly discussing the literature and recent developments. Section 3 provides details on the scenarios considered. Section 4 discusses modeling results on the cost-effective role of land based greenhouse gas mitigation in achieving climate stabilization targets. The section analyzes the data from a number of perspectives, including mitigation levels and timing, the relative role of land based mitigation, the implications of alternative baselines and stabilization targets, and the importance of biomass mitigation strategies. In Section 5, we briefly reflect upon the forest mitigation results from the stabilization scenarios by comparing them to detailed forest sector modeling estimates of forest carbon sequestration supply responses. We conclude with summary remarks and notes on key modeling challenges.

\section{Background}

Changes in land use and land cover represent an important driver of net greenhouse gas (GHG) emissions. Over the past several centuries, human intervention has markedly changed land surface characteristics, in particular through large scale land conversion for cultivation (Vitousek et al., 1997). Cumulative carbon dioxide $\left(\mathrm{CO}_{2}\right)$ emissions from historical land cover conversion for the period 1920 1992 have been estimated to be between 56 and 91 GtC (McGuire et al., 2001), and as much as $148.6 \mathrm{GtC}$ for the entire industrial period $1850-2000$, roughly a quarter to a third of total anthropogenic $\mathrm{CO}_{2}$ emissions over this period (Houghton, 2008). In the 1990s, an average $6.4 \mathrm{GtC} / \mathrm{yr}$ was emitted to the atmosphere from fossil fuel combustion and industrial sources, while the net flux from global land use was estimated at approximately $1.5 \mathrm{GtC} / \mathrm{yr}$, primarily from tropical deforestation (Houghton, 2008). Land management activities such as cropland fertilization and water management, manure management, and forest rotation also affect emissions of $\mathrm{CO}_{2}$ and non- $\mathrm{CO}_{2}$ GHGs. Agricultural land management activities are estimated to contribute approximately $50 \%$ of global atmospheric inputs of methane $\left(\mathrm{CH}_{4}\right)$ and $75 \%$ of global nitrous oxide emissions $\left(\mathrm{N}_{2} \mathrm{O}\right)$, for a net contribution from non- $\mathrm{CO}_{2}$ GHGs of approximately $14 \%$ of all anthropogenic greenhouse gas emissions (USEPA, 2006a).

Changes in land use practices could be an important component of long term strategies to mitigate climate change. Modifications to land use activities can reduce emissions of both $\mathrm{CO}_{2}$ and non- $\mathrm{CO}_{2}$ gases $\left(\mathrm{CH}_{4}\right.$ and $\left.\mathrm{N}_{2} \mathrm{O}\right)$, increase sequestration of atmospheric $\mathrm{CO}_{2}$ into plant biomass and soils, and produce biomass fuel substitutes for fossil fuels. Previous studies have suggested that land has the technical potential to sequester up to an additional $87 \mathrm{GtC}$ by 2050 in global 
forests alone (IPCC, 1995, 2000, 2001). In addition, current technologies are capable of significantly reducing $\mathrm{CH}_{4}$ and $\mathrm{N}_{2} \mathrm{O}$ emissions from agriculture (DeAngelo et al., 2006; USEPA, 2006b).

Unlike energy-related emissions modeling, detailed direct comparisons and evaluations have not yet been made of the integrated assessment land modeling work that has begun to emerge. Until recently, assessment of the long-term role of global land-based mitigation had not been formally addressed in the IPCC's research assessments, including the Special Report on Land use, Land-use Change, and Forestry (IPCC, 2000) and the IPCC's 2001 Working Group III Third Assessment Report on Mitigation (IPCC, 2001). In the Fourth Assessment Report, some attention was given to this issue (Fisher et al., 2007).

Long-term energy modelers have historically focused their attention and time on characterizing energy and industry GHG emissions and mitigation opportunities, which, as noted, are the source of the majority of total GHG emissions (IPCC, 2001). However, this situation has been changing. There is growing regional and international policy interest in land-related GHG mitigation options, ${ }^{2}$ and recent developments in global non- $\mathrm{CO}_{2}$ emissions inventories (Olivier, 2002; USEPA, 2006a; Rose et al., 2009), international agricultural mitigation cost data (DeAngelo et al., 2006; USEPA, 2006b; Beach et al., 2008), and land sector economic modeling (e.g., Rokityanskiy et al., 2007; Sands and Leimbach, 2003; Sohngen and Sedjo, 2006) have facilitated explicit land modeling in climate stabilization analyses that considers the broad set of land related GHG fluxes, sources, and mitigation options.

A stabilization scenario is a particular application of top-down modeling that identifies a dynamic cost-effective portfolio of abatement strategies composed of the lowest cost combination of mitigation strategies over time from across all sectors of the economy that achieve the climate stabilization goal. ${ }^{3}$ This increasingly includes land-use related activities. Many estimates of mitigation potential in the literature are referred to as "bottom-up" estimates in that they are derived from detailed technological engineering and process data and cost data for individual technologies as applied at specific locations (e.g., USEPA, 2006b). These studies estimate how much mitigation is economic for a given GHG price and their estimates facilitate the introduction of emissions abatement technologies into top-down models that are more aggregate. ${ }^{4}$ Top-down models are used to evaluate the cost competitiveness of mitigation options and the implications across input markets, sectors, and regions over time for large-scale domestic or global adoption of mitigation technologies. Top-down models can take many forms-e.g., sectoral, national, economy-wide, and global integrated assessment. It is important to note that while both the bottom-up and stabilization modeling approaches can generate estimates of mitigation potential, the

\footnotetext{
2 See, for example, the emissions reduction offset provisions in United States Congressional legislative proposals (e.g., Senate Bill S.2191 in the 110th Congress, the Lieberman-Warner Climate Security Act of 2008), and the approaches for reducing emissions from deforestation and degradation (REDD) in the United Nations Framework Convention on Climate Change's Bali road map (http://unfcccbali.org/ unfccc/).

${ }^{3}$ In integrated assessment and economic climate stabilization scenarios, a climate target is prescribed (e.g., atmospheric concentration or radiative forcing level) and modeling identifies the cost-effective (i.e., least-cost) combination of mitigation technologies over time for realizing the climate target. This is inherently different from the economic optimization of discounted net benefits, where the difference between monetized benefits and costs is maximized and the climate outcome is derived. See Sohngen and Mendelsohn (2003) for an example of this later approach. Comparison of results from the two approaches is problematic because setting a climate target yields both monetized and non-monetized benefits, and non-monetized benefits are likely significant, while optimization is based solely on monetized benefits.

${ }^{4}$ In Integrated Assessment Models, a price can be associated with greenhouse gas emissions in various forms (tax, international allowance market, shadow price), and the price can involve only $\mathrm{CO}_{2}$ emissions or all greenhouse gases. Throughout this paper we use the term 'GHG price' as a generic term for the price associated with greenhouse gas emissions.
}

estimates are not always directly comparable. Most importantly, bottom-up estimates are frequently estimates of how much mitigation is available at a given GHG price, while stabilization estimates are estimates of how much mitigation is used to achieve the given environmental goal at the lowest cost (from which an implied GHG price can be inferred). ${ }^{5}$ The scenarios discussed in this paper are all applications of the top-down approach.

The notion that forest sequestration could be used to offset GHG emissions and stabilize climate is not new (see Dyson, 1977; Lashof and Tirpak, 1989; Marland, 1988). Furthermore, recent studies explicitly modeling land use and land use change have provided rigorous modeling showing how the costs of achieving long-run climate objectives can be reduced (Sands and Leimbach, 2003; Sohngen and Mendelsohn, 2003). Sands and Leimbach (2003) consider the role of a composite energy crop in stabilization, and Sohngen and Mendelsohn (2003) consider the role of forestry in economically optimal mitigation. The scenarios presented in this paper build upon the literature by assessing more complete sets of competing land mitigation options across a number of models in achieving common climate stabilization goals. In this context, landbased mitigation technologies compete with each other and with mitigation technologies in other sectors of the economy regionally and globally. Global and long-run land modeling of the kind reported in this paper is essential for evaluating large scale changes in land-use that will have global market and biophysical implications that affect land's carbon cycle and climate role, as well as other sectors of the economy. While not the appropriate models for analyzing the fine details of near-term land use decisions in specific locations, global models are capable of capturing essential factors in land-use decisions, such as scarcity and interactions between land-use activities, and providing insights on large-scale phenomena.

\section{Models and scenarios considered}

We consider stabilization results from four models used in a recent Energy Modeling Forum (EMF) coordinated study of climate stabilization, as well as more recent stabilization results from two of the modeling teams that participated in the EMF study. The 21st study of the EMF (EMF-21) assembled modeling teams from around the world in order to evaluate the cost-effectiveness of non- $\mathrm{CO}_{2}$ greenhouse gas mitigation options in stabilizing radiative forcing, i.e., whether or not they lower the cost of stabilization. The results from each of the individual modeling teams have been published in a special issue of The Energy Journal (see Weyant et al., 2006). ${ }^{6}$ EMF-21 was the first time many climate economic and integrated assessment models included non- $\mathrm{CO}_{2}$ greenhouse gas mitigation options, as well as forest carbon sequestration mitigation options. Given EMF-21's focus on the overall mitigation picture, land's specific role in stabilization received little attention. Land use related emissions and mitigation were modeled by a number of the modeling teams, but few land related results or modeling details were provided and no analysis was done of the land results across models.

With a common radiative forcing stabilization target $\left(4.5 \mathrm{~W} / \mathrm{m}^{2}\right)$ and four models including broad sets of land-use related mitigation measures, the EMF-21 exercise provides a unique opportunity for exploring and comparing the details of integrated assessment land

\footnotetext{
${ }^{5}$ There are also meaningful structural differences in the two approaches. Bottom-up mitigation responses typically are significantly more detailed. Given their focus on detailed technologies, the modeling tends to employ more extensive fixed market assumptions. Cost estimates are therefore more partial equilibrium in that some input and output market prices are exogenous as can be key input quantities such as acreage or capital. Top-down mitigation responses consider more generic mitigation technologies and more endogenous changes in outputs and inputs (e.g., shifts from food crops or forests to energy crops) as well as changes in market prices (e.g., changes in land prices with increased competition for land).

${ }^{6}$ For more information on EMF-21, go to www.stanford.edu/group/EMF/.
} 
modeling. The GRAPE, IMAGE, MESSAGE and GTEM models explicitly modeled the cost-effectiveness of including land based mitigation in the least-cost portfolio of mitigation strategies for climate stabilization (respectively, Jakeman and Fisher, 2006; Kurosawa, 2006; Rao and Riahi, 2006; van Vuuren et al., 2006a, 2006b). We have compiled and analyzed data for the scenarios from these teams on the characterization and role of land-use related mitigation measures. The paper also includes analysis of more recent stabilization results from two of the modeling teams that have subsequently improved upon their EMF-21 land modeling (Riahi et al., 2007; van Vuuren et al., 2007). ${ }^{7}$

Table 1 presents an overview of land modeling characteristics for each of the studies considered. Table 1 illustrates that there are clear differences in modeling. For instance, the models have fairly similar land type, emissions, and sequestration coverage. However, there are differences in the geographic resolution at which land quality/ productivity differences are captured as well as differences in the mitigation options available. As far as mitigation options, only GTEM includes additional forest carbon from changes in forest management (e.g., longer rotations and management intensification via thinning and fertilization), while IMAGE does not include avoided deforestation, in contrast to MESSAGE, GRAPE, and GTEM. On the other hand, GTEM did not include bioenergy, while the other models model different combinations of biomass feedstocks, bioenergy demands, and available land for dedicated bioenergy feedstocks.

The models also differ in their implementation of land-based mitigation into their overall frameworks. The integrated assessment and general equilibrium models represented here have relied on detailed sectoral models or engineering studies to model the costs of forest and agricultural mitigation respectively (see Appendix). While different, each of these approaches captures agriculture and forestry management changes and estimates output and commodity price implications. How, depends on the implementation approach. For example, GTEM introduces sequestration supply curves from the global forestry model of Sohngen and Sedjo (2006) into its general equilibrium model, and MESSAGE iterates energy models with land sector models in an integrated assessment modeling framework. Finally, van Vuuren et al. (2006a, 2006b, 2007) used afforestation supply curves derived from IMAGE calculations as shown in Strengers et al. (2008). ${ }^{8}$ Currently, abatement supply schedules (or marginal abatement curves, MACs) from DeAngelo et al. (2006) are used in modeling agricultural non- $\mathrm{CO}_{2}$ GHG mitigation costs and GHG reduction potential. However, there is no standard practice for how these MACs are implemented. Only GTEM (Jakeman and Fisher, 2006) has fully endogenous agricultural mitigation costs (but exogenous forestry mitigation). The other models implement the agricultural MACs with some degree of exogeneity. While the models differ in terms of endogeneity, none of the models include the negative cost abatement sometimes shown in MACs, which could be regarded as being "profitable." This handling is consistent with the interpretation in DeAngelo et al. (2006) and USEPA (2006b) that there are unaccounted for costs and barriers that explain why these options are not already adopted. The models also do not include transaction costs, which is discussed further in the concluding section.

Table 1 provides a high level comparison of land modeling approaches. Additional differences are evident in finer details. See the Appendix for descriptions of each model's land modeling approach, which includes, among other things, descriptions of the land allocation, emissions, and mitigation approach. The appendix also includes a summary comparison table with additional modeling specifics. For

\footnotetext{
7 These land modeling and overall IAM frameworks have also been employed in subsequent studies in addressing other research questions (e.g., the Clarke et al., 2009).

8 Each of these approaches captures biomass carbon saturation by modeling the carbon sequestration dynamics of soils and above ground biomass. However, agricultural soil carbon abatement options are currently not modeled by integrated assessment models.
}

example, while all the models model cropland, some model an aggregate crop while others model a variety of crops, and land allocation across alternative uses is managed with different approaches, some models giving priority to food production. These unique characteristics, in addition to other factors, imply different opportunities and opportunity costs for land related mitigation; and, therefore, suggest different outcomes are likely under similar climate policies.

\section{Results: cost-effective land-based mitigation in climate stabilization}

Overall, the four modeling groups found that it was cost-effective to include land based mitigation in the set of eligible stabilization strategies. In other words, all the models found that they could lower the cost of stabilization by using land based mitigation in lieu of some non-land options. This result is in line with the overall findings of EMF-21 that including non- $\mathrm{CO}_{2}$ mitigation measures provides greater flexibility within and across time periods and therefore lowers costs (Weyant et al., 2006). ${ }^{9}$

What is of greatest interest however is the size of land's mitigation contribution, not the conclusion that having more mitigation options will lower costs (or be no worse). Jakeman and Fisher (2006) provided an explicit estimate of the cost savings associated with including land-use change and forestry mitigation options. Including agriculture and forestry options reduced the emissions reduction burden on all other emissions sources such that the projected decline in global real GDP associated with achieving stabilization was reduced to $2.3 \%$ in 2050 (US\$3.6 trillion in 2003 dollars), versus losses of around $7.1 \%$ (US\$11.2 trillion) and 3.3\% (US\$5.2 trillion) for the $\mathrm{CO}_{2}$ only and multi-gas (without forest sinks) scenarios respectively. None of the EMF-21 papers isolated the GDP effects associated with biomass fuel substitution or agricultural non- $\mathrm{CO}_{2}$ abatement. As is shown below in the next section, all of the studies listed in Table 1 find that each of agriculture, forest, and biomass mitigation strategies to be cost-effective and to lower the cost of stabilization.

\subsection{Magnitude, timing, and relative roles}

Figs. 2 and 3 present snapshots of annual abatement for four years from the mitigation trajectories of the four EMF-21 models in achieving the $4.5 \mathrm{~W} / \mathrm{m}^{2}$ stabilization target compared to pre-industrial times (see Rose et al., 2008, for the full trajectories and tabular annual results). ${ }^{10}$ Fig. 2 depicts the dynamic abatement roles of "Land" and all "Other" activities in the stabilization emissions abatement trajectories. Total Land abatement includes net reductions from agriculture, forest, and biomass. Total "Other" abatement includes GHG reducing activities not associated with land-use, e.g., non-biomass energy, industry, and transportation activities. Fig. 3 disaggregates the annual land abatement into agricultural non- $\mathrm{CO}_{2}$ emissions reductions $\left(\mathrm{CH}_{4}\right.$ and $\left.\mathrm{N}_{2} \mathrm{O}\right),{ }^{11}$ additional forest carbon sequestration, and commercial biomass related abatement. Biomass abatement from the MESSAGE model is further subdivided into biomass sequestration and biomass energy combined with $\mathrm{CO}_{2}$ capture and geologic storage (BECS). In both Fig. 2 and Fig. 3, the upper boundary of the bar stack represents baseline emissions in that year, in total and for the land sectors respectively. Therefore, agricultural and forestry mitigation represent emissions reductions or additional terrestrial sequestration from the baseline respectively, while biomass mitigation represents offsets of fossil fuel

\footnotetext{
${ }^{9}$ While there are clear differences among the models at any point in time, the marginal costs were reduced by $30-60 \%$ on average, and GDP losses were reduced 30-40\% (van Vuuren et al., 2006a, 2006b).

${ }^{10}$ Note that the GTEM model time horizon is 2050, while the time horizon is 2100 for the other models. Also, GTEM explicitly models fossil fuel $\mathrm{CO}_{2}$ emissions abatement in agriculture. The others do not.

${ }^{11}$ Recall that none of the models consider agriculture soil carbon enhancement options.
} 
Table 1

Overview of stabilization modeling studies considered (2100 radiative forcing relative to pre-industrial times)

\begin{tabular}{|c|c|c|c|c|c|c|}
\hline Scenario source & Kurosawa (2006) & $\begin{array}{l}\text { van Vuuren et al. } \\
\text { (2006a, 2006b) }\end{array}$ & Rao and Riahi (2006) & Jakeman and Fisher (2006) & Riahi et al. (2007) & van Vuuren et al. (2007) \\
\hline Primary model name & GRAPE & IMAGE 2.2 & MESSAGE & GTEM & MESSAGE & IMAGE 2.3 \\
\hline Climate policies (1) & $\begin{array}{l}\text { Stabilize radiative } \\
\text { forcing with } 4.5 \mathrm{~W} / \mathrm{m}^{2} \\
\text { in } 2100\end{array}$ & $\begin{array}{l}\text { Stabilize radiative } \\
\text { forcing with } 4.5 \mathrm{~W} / \mathrm{m}^{2} \\
\text { in } 2100 \text {. (2) }\end{array}$ & $\begin{array}{l}\text { Stabilize radiative } \\
\text { forcing with } 4.5 \text { and } \\
3.0 \mathrm{~W} / \mathrm{m}^{2} \text { in } 2100\end{array}$ & $\begin{array}{l}\text { Stabilize radiative forcing } \\
\text { with } 3.3 \mathrm{~W} / \mathrm{m}^{2} \text { in } 2050 \text { (based } \\
\text { on } 4.5 \mathrm{~W} / \mathrm{m}^{2} 2100 \text { target) }\end{array}$ & $\begin{array}{l}\text { Stabilize radiative forcing with } \\
4.5 \mathrm{~W} / \mathrm{m}^{2} \text { in } 2100 \text { with alternative } \\
\text { baselines. (2) }\end{array}$ & $\begin{array}{l}\text { Stabilize } \mathrm{CO}_{2} \text { eq concentrations } \\
\text { with } 650,550 \text {, and } 450 \mathrm{ppm} \text { in } \\
2100\left(\sim 4.5,3.7 \text {, and } 2.9 \mathrm{~W} / \mathrm{m}^{2}\right)\end{array}$ \\
\hline In EMF-21 & Yes & Yes & Yes & Yes & No & No \\
\hline Model type & Integrated assessment & Integrated assessment & $\begin{array}{l}\text { Energy model in integrated } \\
\text { assessment framework }\end{array}$ & Computable general equilibrium & $\begin{array}{l}\text { Energy model in integrated } \\
\text { assessment framework }\end{array}$ & Integrated assessment \\
\hline \multicolumn{7}{|l|}{ Land types modeled } \\
\hline Cropland & $\mathrm{x}$ & $\mathrm{x}$ & $\mathrm{x}(3)$ & $\mathrm{x}$ & $\mathrm{x}$ & $\mathrm{x}$ \\
\hline Pasture/grassland & $\mathrm{x}$ & $\mathrm{x}$ & $\mathrm{x}(3)$ & $\mathrm{x}$ & $\mathrm{x}$ & $\mathrm{x}$ \\
\hline Forest & $\mathrm{x}$ & $\mathrm{x}$ & $\mathrm{x}(3)$ & $\mathrm{x}$ & $\mathrm{x}$ & $\mathrm{x}$ \\
\hline Other land cover & Urban & 6 other types & & & Urban & 6 other types \\
\hline Resolution of land quality & Regional & 0.5 degree grid & 0.5 degree grid & regional & 0.5 degree grid & 0.5 degree grid \\
\hline $\begin{array}{l}\text { Land-use GHG emissions/ } \\
\text { sequestration represented }\end{array}$ & & & & & & \\
\hline LUCF & $\mathrm{CO}_{2}$ & $\mathrm{CO}_{2}(4)$ & $\mathrm{CO}_{2}$ & $\mathrm{CO}_{2}$ & $\mathrm{CO}_{2}(4)$ & $\mathrm{CO}_{2}(4)$ \\
\hline Livestock & Non- $\mathrm{CO}_{2}$ & Non- $\mathrm{CO}_{2}$ & Non- $-\mathrm{CO}_{2}$ & Non- $\mathrm{CO}_{2}$ & Non- $\mathrm{CO}_{2}$ & Non- $\mathrm{CO}_{2}$ \\
\hline Crops & Non- $\mathrm{CO}_{2}$ & Soil carbon and non- $\mathrm{CO}_{2}$ & Non- $\mathrm{CO}_{2}$ & Fossil fuel $\mathrm{CO}_{2}$ and non- $\mathrm{CO}_{2}$ & Non- $\mathrm{CO}_{2}$ & Soil carbon and non- $\mathrm{CO}_{2}$ \\
\hline $\mathrm{Ag}$ waste burning & Non- $-\mathrm{CO}_{2}$ & Non- $-\mathrm{CO}_{2}(4)$ & Non- $-\mathrm{CO}_{2}$ & Non- $-\mathrm{CO}_{2}$ & Non- $-\mathrm{CO}_{2}(4)$ & Non- $\mathrm{CO}_{2}(4)$ \\
\hline \multicolumn{7}{|l|}{ Land-based GHG abatement } \\
\hline \multicolumn{7}{|l|}{ Forest } \\
\hline Afforestation & $\mathrm{x}$ & $\mathrm{x}$ & $x(5)$ & $\mathrm{x}$ & $\mathrm{x}$ & $\mathrm{x}$ \\
\hline Forest management & & & & $\mathrm{x}$ & & \\
\hline Avoided deforestation & $\mathrm{x}$ & & $\mathrm{x}(5)$ & $\mathrm{x}$ & $\mathrm{x}$ & \\
\hline \multicolumn{7}{|l|}{ Agriculture (non-energy) } \\
\hline Livestock & Non- $\mathrm{CO}_{2}$ MACs & Non- $\mathrm{CO}_{2}$ MACs & Non- $\mathrm{CO}_{2}$ MACs & Endogenous & Non- $\mathrm{CO}_{2}$ MACs & Non- $\mathrm{CO}_{2}$ MACs \\
\hline Crop & Non- $\mathrm{CO}_{2}$ MACs & Non- $\mathrm{CO}_{2}$ MACs & Non- $\mathrm{CO}_{2}$ MACs & Endogenous & Non- $\mathrm{CO}_{2}$ MACs & Non- $\mathrm{CO}_{2}$ MACs \\
\hline Fossil fuel & Not explicitly & Not explicitly & Not explicitly & Endogenous & Not explicitly & Not explicitly \\
\hline \multicolumn{7}{|l|}{ Bioenergy } \\
\hline \multicolumn{7}{|l|}{ Supply } \\
\hline Dedicated feedstock & & Maize, sugar, woody crops & Woody crops & & Woody crops & Maize, sugar, woody crops \\
\hline Residues & Ag, forest, waste & & & & & $\mathrm{Ag}$, forest, waste \\
\hline $\begin{array}{l}\text { Land available for } \\
\text { dedicated feedstocks }\end{array}$ & Not included & Abandoned ag & $\begin{array}{l}\text { Forest, grassland, savannah, } \\
\text { abandoned }\end{array}$ & & $\begin{array}{l}\text { Forest, grassland, savannah, } \\
\text { abandoned }\end{array}$ & $\begin{array}{l}\text { Grassland, savannah, } \\
\text { abandoned ag }\end{array}$ \\
\hline \multicolumn{7}{|l|}{ Demand } \\
\hline Transportation & $\mathrm{x}$ & $\mathrm{x}(6)$ & $\mathrm{x}$ & & $\mathrm{x}$ & $\mathrm{x}$ \\
\hline Electricity & $\mathrm{x}$ & $x(6)$ & $\mathrm{x}$ & & $\mathrm{x}$ (with and without BECS) & $\mathrm{x}$ (with and without BECS) \\
\hline $\begin{array}{l}\text { Other (e.g., hydrogen, } \\
\text { gas, CHP, end-use) }\end{array}$ & Stationary use & $\mathrm{x}(6)$ & $\mathrm{x}$ & & $\mathrm{x}$ & $\mathrm{x}$ \\
\hline
\end{tabular}

Notes: LUCF = Land Use Change and Forestry net emissions (e.g., deforestation, afforestation, reforestation, grassland conversion); MAC = Marginal Abatement Curve

(1) Radiative forcing levels in 2100. Stabilization targets below $4.5 \mathrm{~W} / \mathrm{m}^{2}$ do not stabilize until 2100.

(2) Additional stabilization targets run. Detailed land mitigation data only available for $4.5 \mathrm{~W} / \mathrm{m}^{2}$ scenario

(3) Land not explicitly modeled in Rao and Riahi (2006) core scenarios. However, cropland, forest, and forest bioenergy land are modeled in the sensitivity scenarios.

(4) Air pollutant emissions also modeled.

(5) Based on the sensitivity analysis of Rao and Riahi (2006) that used the DIMA model.

(6) IMAGE 2.2 bioenergy substitution limited to substitution with natural gas and oil. 


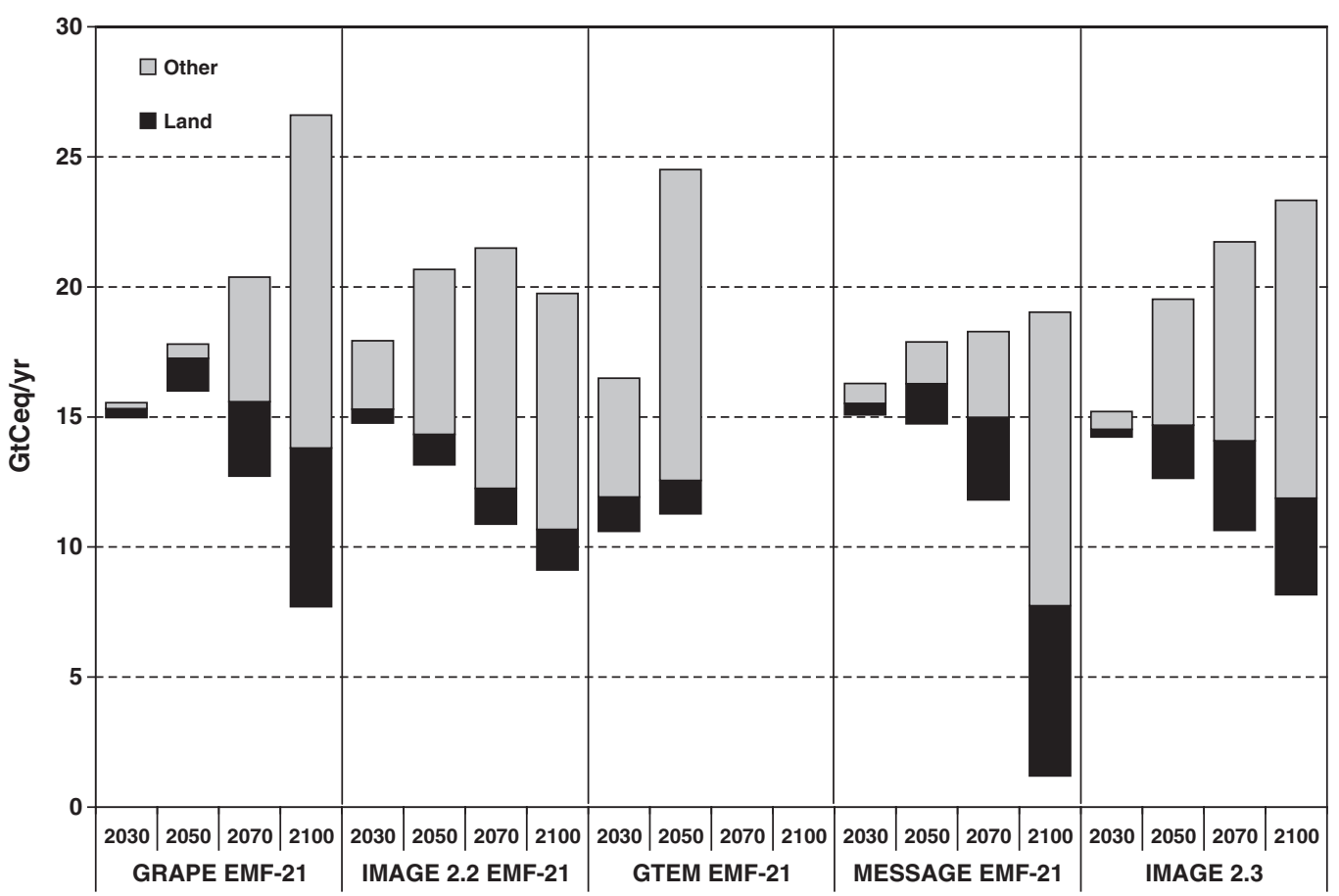

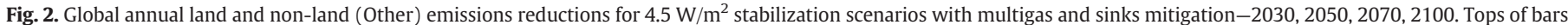
are annual baseline emissions levels.

combustion emissions, or bioenergy combustion emissions in the case of BECS. As a result, total land abatement produces a large net sequestration (vs. net emissions) effect in some of the scenarios (see Fig. 3 where the bottom boundary projects negative remaining land emissions).

There are clear differences in abatement trajectory mitigation levels, timing, and mix. The magnitude of abatement in any particular time period - overall, from land, and from the specific land abatement categories - varies across models. For example, in 2050, forests abate
$1 \mathrm{GtCeq} / \mathrm{yr}$ with the GRAPE model, while the IMAGE, GTEM, and MESSAGE models project forest abatement of 0.4, 0.6, $0.1 \mathrm{GtCeq} / \mathrm{yr}$ respectively (Rose et al., 2008). Similarly, GTEM projects approximately $0.4 \mathrm{GtCeq} / \mathrm{yr}$ of agricultural nitrous oxide abatement in 2050, while the other models project $0.2 \mathrm{GtCeq} / \mathrm{yr}$ or less.

When bioenergy is modeled, annual bio-energy mitigation grows more quickly than the other options over time and becomes the dominant strategy (discussed more below and in Section 4.4). Forestry is the next most dominant strategy annually. Annual forest

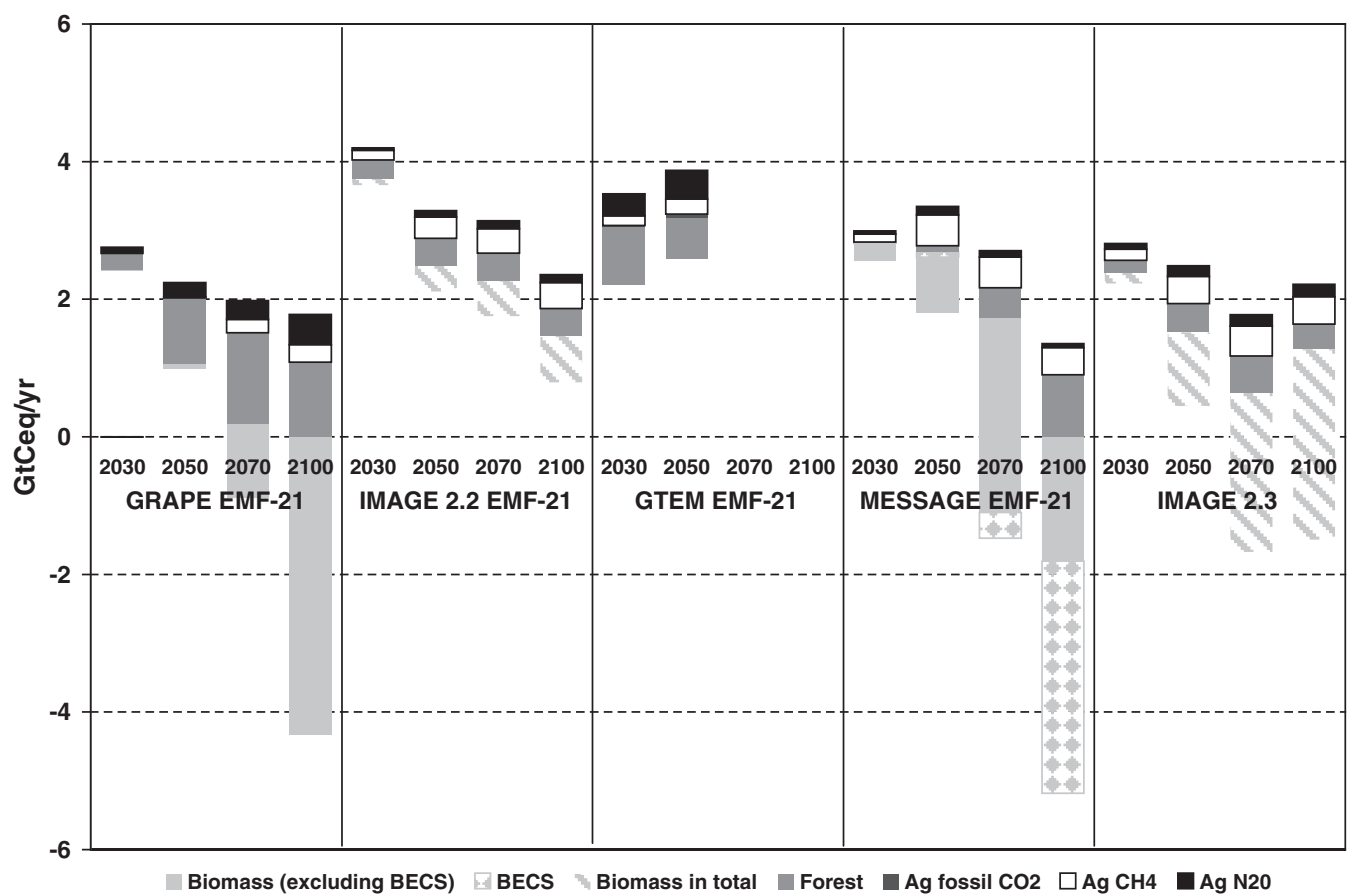

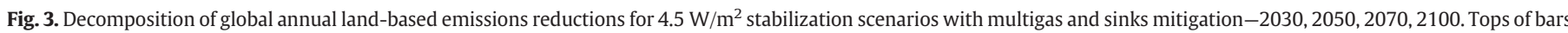
are annual baseline emissions levels. 
mitigation grows or remains fairly constant over time for all the models except GTEM, which shows a slight decline in forest mitigation that is offset by an increase in agricultural mitigation. ${ }^{12}$ Agricultural $\mathrm{CH}_{4}$ mitigation is significant for IMAGE and MESSAGE, while agricultural $\mathrm{N}_{2} \mathrm{O}$ abatement is relatively more important in magnitude than agricultural $\mathrm{CH}_{4}$ for GRAPE and GTEM.

Reviewing annual abatement is useful for gaining insights into pathways and the relative magnitude of mitigation over time. However, given potential annual variability due to assumptions about things like forest inventories and changes in relative technology costs, cumulative abatement is a more robust metric for evaluating land's relative abatement role. In Table 2 , we have computed cumulative abatement by activity type for different time periods: 2000-2030, 2000-2050, and 2000-2100. The upper block of results in Table 2 corresponds to the annual emissions reductions for the $4.5 \mathrm{~W} / \mathrm{m}^{2}$ EMF-21 stabilization scenarios illustrated in Figs. 2 and 3. The lower block of results in Table 2 corresponds to scenarios discussed in subsequent sections (including an additional $4.5 \mathrm{~W} / \mathrm{m}^{2}$ MESSAGE scenario that is discussed later).

In Table 2 and Figs. 2 and 3, very different responses for $4.5 \mathrm{~W} / \mathrm{m}^{2}$ are observed across models due to the confluence of numerous uncertainties-including baseline emissions, mitigation option sets, and the relative costs of land mitigation options with respect to each other and non-land options. With many factors and interactions affecting the resulting land-based mitigation within a model, it is difficult to attribute specific differences in mitigation quantities across models directly to one or even two specific factors. However, relative differences in mitigation responses across models can be attributed to modeling differences (Table 1 and the Appendix). For instance, IMAGE 2.2 has significantly less land-based abatement cumulatively and in most years than GRAPE, MESSAGE, and even IMAGE 2.3 due in large part to more limited forestry and bioenergy options, and available land for those activities. The differences between IMAGE 2.2 and IMAGE 2.3 abatement are due primarily to the introduction of more bioenergy options in IMAGE 2.3. Meanwhile, differences in land competition are also affecting relative results. For example, GRAPE has a larger forest abatement response than MESSAGE due in part to a lower internal opportunity cost for forest abatement. GRAPE does not include dedicated bioenergy land uses as a bioenergy feedstock, while MESSAGE only includes dedicated woody bioenergy land uses that directly compete for land with forests (Table 1). GTEM has less cumulative abatement than the other models through 2050 primarily because it does not include bioenergy options. However, early cumulative forestry abatement in GTEM is much larger than the other models with abatement through 2030 of $12.7 \mathrm{GtC}$, versus the next largest, IMAGE 2.2 at $4.8 \mathrm{GtC}$, and MESSAGE with only $0.1 \mathrm{GtC}$. The GTEM result is in part due to using forestry sequestration supply estimated with a constant carbon price versus a rising price, where the later results in delayed abatement as land owners look to take advantage of higher future carbon prices. ${ }^{13}$ Differences in agricultural abatement are particularly difficult to disentangle given differences in food demand as well as land and mitigation modeling. GTEM, for instance, is the only model to fully endogenize agricultural emissions abatement and directly tie emissions and mitigation to drivers, thus capturing interactions across agricultural sectors (e.g., crop and livestock production) and allowing for explicit input substitution for reducing emissions (e.g., fertilizer substitution). The larger GTEM

\footnotetext{
12 The GTEM result (Jakeman and Fisher, 2006) is highly dependent on the GTEM implementation of forest carbon responses from Sohngen and Sedjo (2006) where profitable rotational harvesting is projected mid-century. Also, Jakeman and Fisher implemented a high GHG price scenario from Sohngen and Sedjo that includes a relatively high mitigation response over the early decades.

13 The differences in near-term forestry abatement supply under delayed and constant carbon prices can be large depending on the price levels. For examples, see Sohngen and Sedjo (2006) and USEPA (2005).
}

agricultural $\mathrm{N}_{2} \mathrm{O}$ emissions abatement is in part due to having these emissions tied to fertilizer inputs, while smaller agricultural $\mathrm{CH}_{4}$ abatement is in part due to linking enteric and manure emissions to livestock output. Agricultural non- $\mathrm{CO}_{2}$ GHG abatement in the other models is determined with exogenous abatement supply curves.

While clear differences are seen, the studies also agree on a number of points. First, as already mentioned agriculture, forestry, and biomass mitigation options are all a part of the cost-effective mitigation portfolio in each model. Therefore, each of these abatement categories is helping to lower the overall cost of stabilization. Second, total annual GHG abatement grows over time, with increasing annual abatement in both the "Other" and "Land" sectors. However, "Other" sector annual abatement grows faster than "Land" abatement throughout the century for all four scenarios. Third, land based mitigation strategies are a significant part of the mitigation portfolio, abating 23 to 44 cumulative GtCeq by 2050 (18 to $72 \%$ of total abatement; Table 2) and around 100 to 225 cumulative GtCeq by 2100 (15 to $44 \%) .{ }^{14}$

Lastly, bio-energy mitigation is found to be an extremely important mitigation option, with GRAPE and MESSAGE projecting biomass as the heavily dominant land abatement strategy over the century, leading to $4 \mathrm{GtCeq} / \mathrm{yr}$ abatement in 2100 from both scenarios, for cumulative abatement of 100 and 147 GtCeq by 2100 respectively. Alternatively, the IMAGE EMF- 21 results project $0.7 \mathrm{GtCeq}$ in 2100 for cumulative abatement of $31 \mathrm{GtCeq}$ by 2100 . The more recent IMAGE 2.3 results project substantially more biomass abatement for achieving a similar concentration stabilization target of $650 \mathrm{CO}_{2} \mathrm{eq}$ $\mathrm{ppm}$ (2.8 GtCeq/yr abatement in 2100 , for cumulative abatement of 129 GtCeq by 2100 ). See Section 4.4 below for additional discussion of the biomass results.

In general, the scenarios support the perspective that agriculture and forestry mitigation measures could be an important part of the near-term cost effective abatement strategy, but may not assume most of the near-term abatement burden and be a bridge to future advanced low-carbon technologies. We find that land-based abatement could be as high as $60 \%$, but as low as to $25 \%$, of total abatement in the near-term. However, over the long-run, we also see a significant potential role (15 to $45 \%$ through 2100 ) with continued avoided deforestation and new forests and biomass production. We find modest but notable contributions from agricultural abatement of rice and livestock methane (enteric and manure) and soil nitrous oxide (3-5\% through 2100), with some suggestion of increased relative importance in early decades (7-22\%). It is interesting to note that the bridge role could be more significant if abatement banking is available such that cheaper near-term abatement is undertaken and banked for use in the future in lieu of more expensive abatement. It is important to note however that delays in program design, institutions, and the protocols needed to provide land-based abatement may diminish land's role as a bridge and may even increase emissions (e.g., Rose and Sohngen, 2011).

It should also be noted that while land-based mitigation strategies can make a substantial contribution to the cost effective stabilization portfolio, all the scenarios illustrate the simple fact that, for long-term stabilization, fossil fuel emissions must be addressed - a point that is reinforced by remembering that biomass mitigation - liquid or solid is substituting for fossil fuels.

\subsection{Baseline emissions}

Base year emissions and the trajectory of baseline emissions in the absence of a climate stabilization policy differ across the studies, both

\footnotetext{
14 The high percentage in 2050 comes from scenarios (e.g., GRAPE) that estimate a modest amount of cumulative abatement from 2000 to 2050, with forestry and agricultural abatement options providing the majority of the abatement.
} 
Table 2

Cumulative global land-based mitigation (GHGs) and shares of total abatement (\%) by mitigation source and GHG for various stabilization scenarios by radiative forcing target in 2100 (GtCeq).

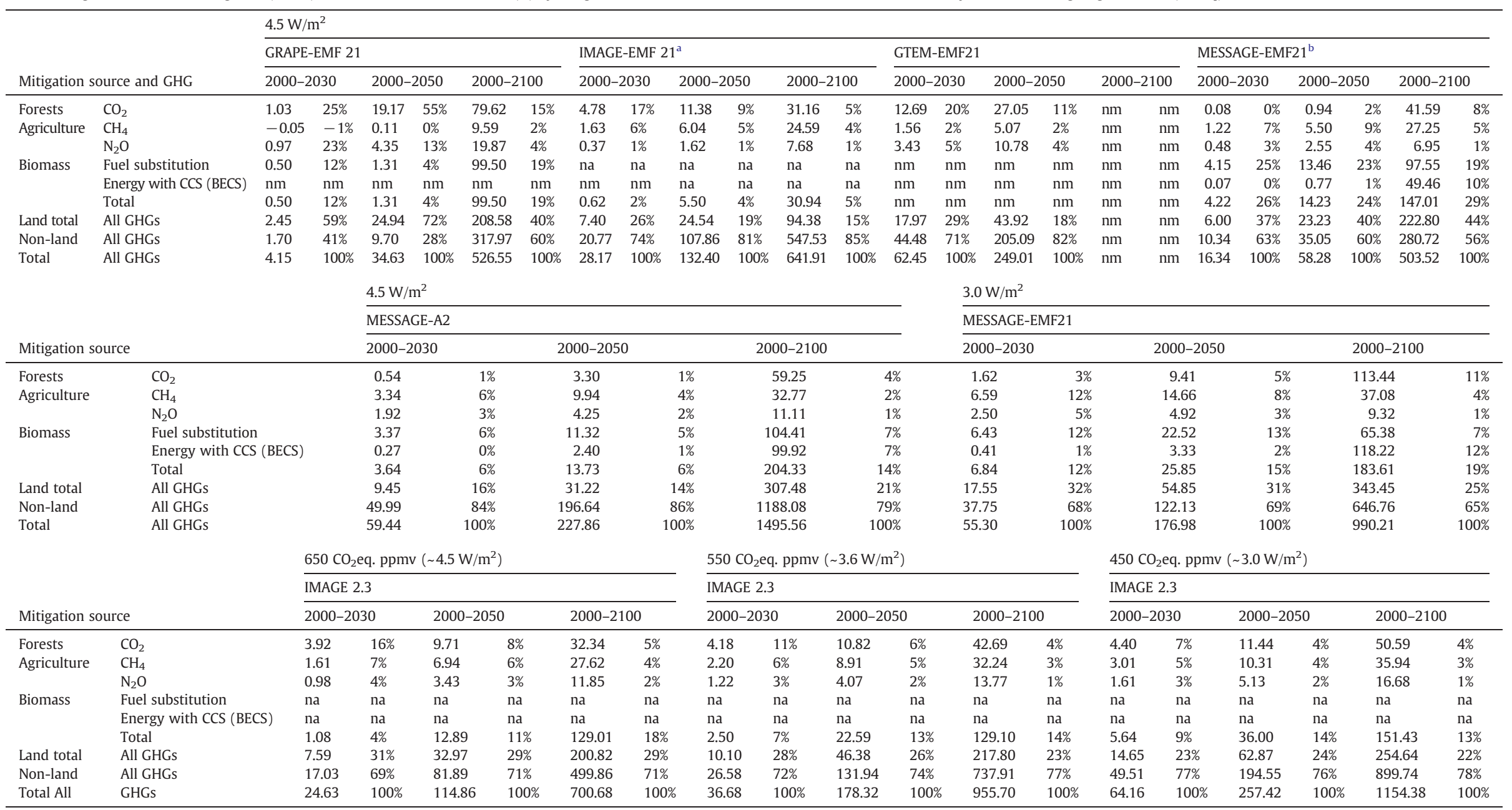

Notes:

The GTEM scenarios ran through 2050 and the GTEM land mitigation totals include fossil fuel $\mathrm{CO}_{2}$ emissions reductions in agriculture of 0.30 and $1.02 \mathrm{GtCeq}$ for $2000-2030$ and $2000-2050$ respectively. The GRAPE model projected an increase in CH4 emissions in 2020.

$\mathrm{nm}=$ not modeled, $\mathrm{na}=$ data not available.

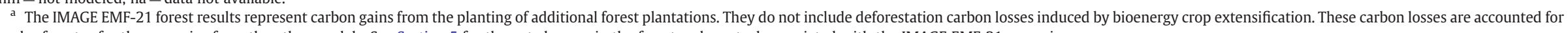
under forestry for the scenarios from the other models. See Section 5 for the net changes in the forest carbon stock associated with the IMAGE EMF-21 scenario.

${ }^{b}$ Results based on the $4.5 \mathrm{~W} / \mathrm{m}^{2}$ MESSAGE scenario from the sensitivity analysis of Rao and Riahi (2006) that used the DIMA model. 
in total and from the land activities. These differences partly explain the differences across results for the role of land-use related mitigation options. Recall that the upper edge of the bar stacks in Figs. 2 and 3 represent the baseline emissions. Some of the studies suggest that baseline total emissions will monotonically increase over the century (GRAPE, MESSAGE, and GTEM), while others suggest that total $\mathrm{CO}_{2}$ equivalent emissions will rise until mid-century and then level-off or decline over the remainder of the century (IMAGE 2.2). Underlying these baseline emissions differences are different population, economic growth, and technological change projections and therefore different emissions generation processes and economic opportunities. In addition, differences in land-use net emissions baselines can also be attributed to differences in the agricultural emission sources considered and differences in the definitions of forests and deforestation assumptions. For instance, agricultural emission sources vary across the scenarios, with livestock methane, rice paddy methane, and crop soil nitrous oxide emissions consistently represented. However, the handling of biomass burning and fossil fuel combustion emissions varies, and only the IMAGE model accounts for agricultural soil carbon fluxes. Also, GTEM assumes less early and cumulative deforestation over time and more deforestation in later years than the other scenarios.

There is some agreement across models that baseline land emissions will rise early in the century and then decline. The general pattern is consistent with storylines of increasing and then decreasing deforestation pressure as population growth diminishes, agricultural productivity improves, and demand growth for pasture land declines. However, the chronological timing of the apex varies across the models, as does the maximum emissions level over the century (e.g., IMAGE results peak at over $4 \mathrm{GtCeq}$ in 2020, while GRAPE results peak at just less than 3 GtCeq in 2040).

One way to evaluate the mitigation effects of baselines is for a single model to consider alternative baselines in achieving a given stabilization target. The $4.5 \mathrm{~W} / \mathrm{m}^{2}$ stabilization scenarios from Rao and Riahi (2006) and Riahi et al. (2007) provide such an opportunity. Rao and Riahi use a SRES B2 reference and Riahi et al. use, among other things, a revised SRES A2 reference (see Grübler et al., 2007) (Fig. 4, left and center panels respectively). Fig. 4 has top and bottom panels, with total mitigation projections in the top panels and the corresponding land mitigation projections in the bottom panels. The left set of panels is the full annual abatement time profile associated with the MESSAGE-EMF21 results in Figs. 1 and 2, which has a B2 reference. Alternatively, with greater population growth, food demand, and greater reliance on coal, more baseline total and land emissions are generated in the revised A2 reference and, therefore, more mitigation is required from all the conventional technologies (land and non-land) characteristic of A2. Overall, the $4.5 \mathrm{~W} / \mathrm{m}^{2}$ target is more stringent for the $\mathrm{A} 2$ baseline, and therefore more expensive. Specifically, total cumulative mitigation increases to 228 from 58 GtCeq and 1496 from 504 GtCeq by 2050 and 2100 respectively (Table 2), with land-based abatement increasing to 31 from $23 \mathrm{GtCeq}$ and 307 from 223 GtCeq respectively. Almost all of the additional land related mitigation is achieved through biomass strategies, primarily with larger-scale early adoption of biomass energy combined with $\mathrm{CO}_{2}$ capture and storage (BECS).

A comparison of the left and center panels of Fig. 4 also illustrates the importance of constraints on biomass and land-based mitigation potential and their potential influence on projected land outcomes. Biomass and overall land GHG mitigation increases with the A2 baseline relative to the $\mathrm{B} 2$ baseline. However, they are not able to maintain their relative abatement role, as annual abatement in the Other sectors grows more quickly than the growth in annual biomass and land abatement. For instance, biomass' share of cumulative abatement through 2050 falls to $6 \%$ from $24 \%$ and land's overall share falls to $14 \%$ from $40 \%$. This result illustrates, in part, implicit limits both ecological and economic - to biomass and land based mitigation.

\subsection{Alternative stabilization targets}

Does the role of land-use change under tighter stabilization targets? We were able to assemble land results for the $3.0 \mathrm{~W} / \mathrm{m}^{2}$ (in 2100) stabilization scenario in Rao and Riahi (2006) (Fig. 4 right panels), and for the 550 and $450 \mathrm{ppm} \mathrm{CO}_{2}$-equivalent stabilization scenarios in van Vuuren et al. (2007) (Fig. 5), which are approximately equivalent to 3.7 and $2.9 \mathrm{~W} / \mathrm{m}^{2} .{ }^{15}$

As expected, the more stringent stabilization targets require greater total abatement (with greater mitigation expenditures) throughout the century. Additional abatement is used from both the land and non-land using activities, with forestry and biomass providing almost all of the additional land based abatement. For example, cumulative land mitigation jumps from 23 to $55 \mathrm{GtCeq}$ through 2050 and 223 to 343 GtCeq through 2100 in the MESSAGE scenarios when the target tightens from 4.5 to $3 \mathrm{~W} / \mathrm{m}^{2}$, with increases in annual forest and biomass mitigation of approximately 0.1 to 0.7 and 0.9 to $1.4 \mathrm{GtCeq} / \mathrm{yr}$ in 2050 . However, while all of the land strategies contribute increased abatement in the first half of the century, agriculture's share of total land abatement increases in the MESSAGE scenarios, primarily from increased agricultural $\mathrm{CH}_{4}$ abatement while in the second half of the century, forestry assumes a larger share of overall land mitigation. Conversely, as the target is tightened with the IMAGE 2.3 model, biomass abatement assumes an increasing share of growing total land abatement with essentially no change in agricultural abatement and very little increase in the level of forest abatement. In the IMAGE scenarios, agriculture and forestry mitigation are being adopted at lower cost levels and then exhausted as the target tightens. This result may change when avoided deforestation is incorporated into the model in the future. In terms of overall abatement, the scenarios suggest that land's share of cumulative abatement could fall with tighter stabilization targets in the first half of the century and over the entire century (Table 2). This implies an increasing reliance on non-land sector emissions mitigation as the least expensive mitigation measures are exhausted.

\subsection{Mitigation from bio-energy use}

The GRAPE, MESSAGE, and IMAGE 2.3 results suggest that bioenergy could play a substantial role in stabilization. For very low scenarios (e.g. $3 \mathrm{~W} / \mathrm{m}^{2}$ and below) the presence of bio-energy with $\mathrm{CO}_{2}$ capture and storage (BECS) might even be a requirement. ${ }^{16}$ Across scenarios, absolute emissions reductions through the increased use of bio-energy are projected to grow slowly in the first half of the decade and then rapidly in the second half as new bio-energy processing and mitigation technologies become available (Fig. 6). Across the $4.5 \mathrm{~W} / \mathrm{m}^{2}$ stabilization scenarios we find a wide range of cumulative bio-energy mitigation of 31 to 204 GtCeq over the century. The low end of the range is from the IMAGE 2.2 model, which considers a more limited set of bio-energy pathways. ${ }^{17}$ The high end of the range is from the revised A2 high emissions MESSAGE scenario. Most studies have results in the order of 100 to $150 \mathrm{GtCeq}$ for the $4.5 \mathrm{~W} / \mathrm{m}^{2}$ target. The entire range slides up to around 150 to $185 \mathrm{GtCeq}$ for the more stringent stabilization target $\left(3.0 \mathrm{~W} / \mathrm{m}^{2}\right)$.

\footnotetext{
15 Radiative forcing levels in 2100 . The scenarios below $4.5 \mathrm{~W} / \mathrm{m}^{2}$ stabilize after 2100 .

${ }^{16}$ Whether BECS is a requirement for stabilization may depend on whether it is unacceptable to overshoot the radiative forcing target before reaching it (Clarke et al., 2009).

17 IMAGE 2.2 limits land supply for biomass production to abandoned lands; constrains bio-energy substitution opportunities to natural gas and oil, thereby biasing biomass use towards transportation; and, does not include bioenergy from residues. On the other hand, IMAGE 2.3 is able to utilize natural grasslands and savannah as well as abandoned lands (see Hoogwijk et al., 2005); substitute bio-energy generally as a liquid or solid energy feedstock, thereby producing greater electricity use; and, includes bio-energy from residues.
} 

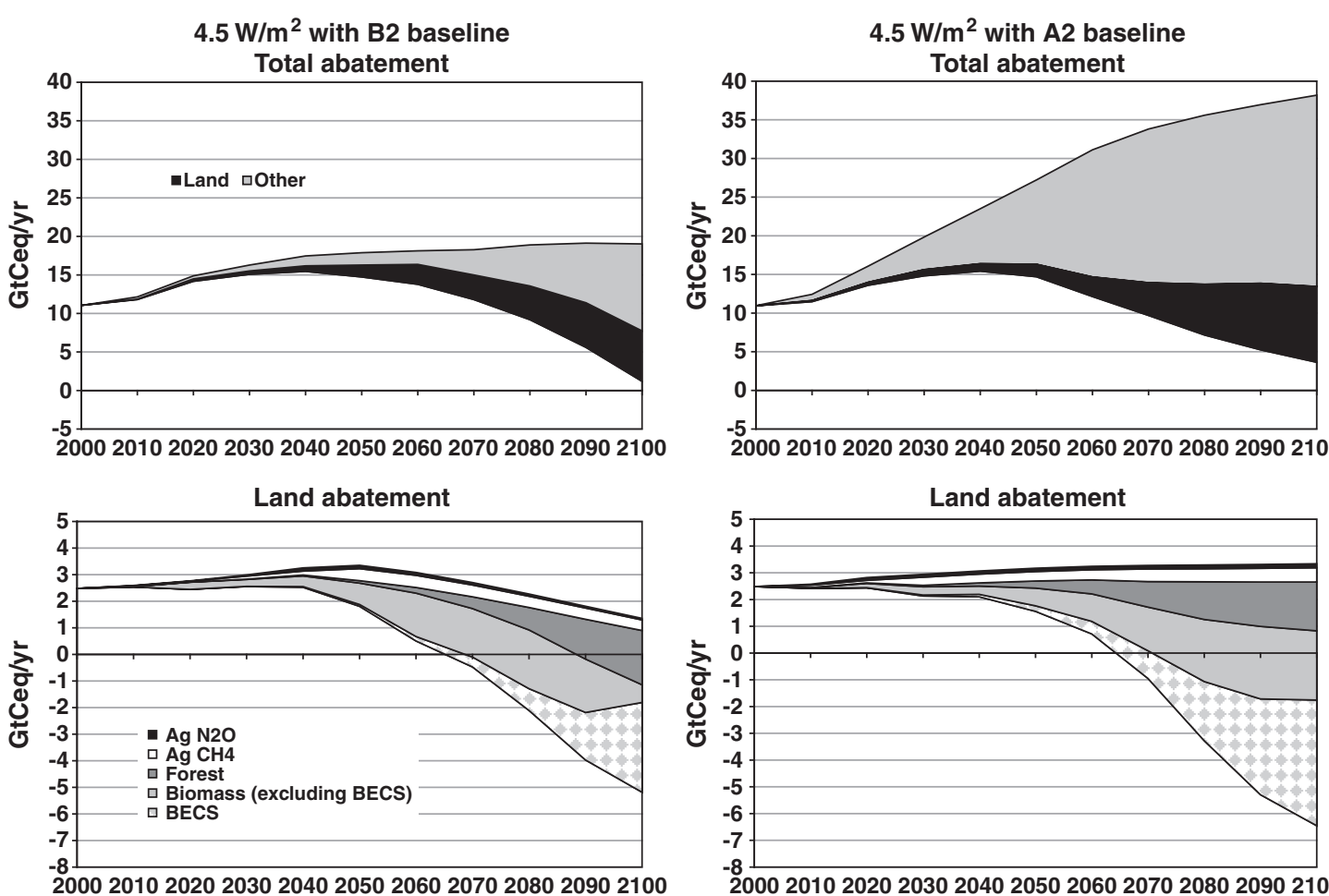
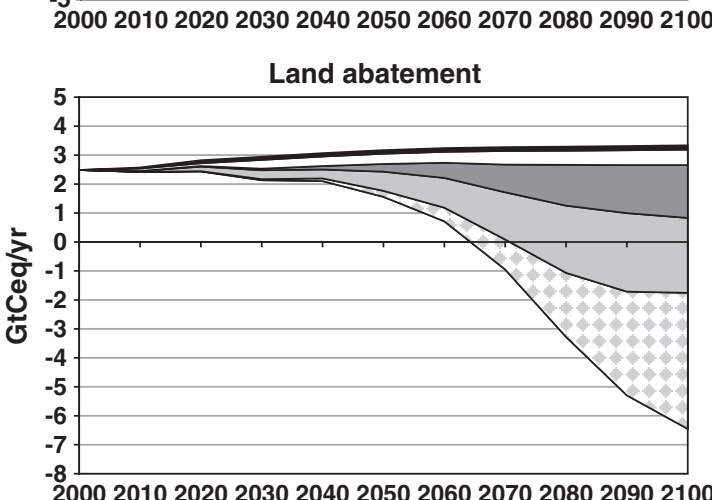

$3.0 \mathrm{~W} / \mathrm{m}^{2}$ with $\mathrm{B} 2$ baseline

Total abatement

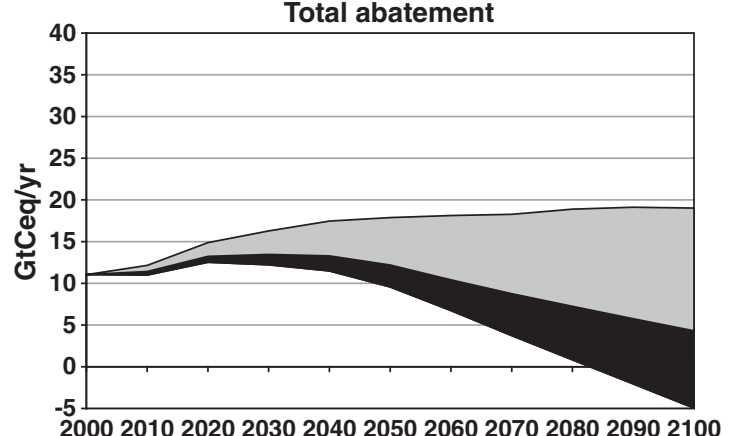

Land abatement

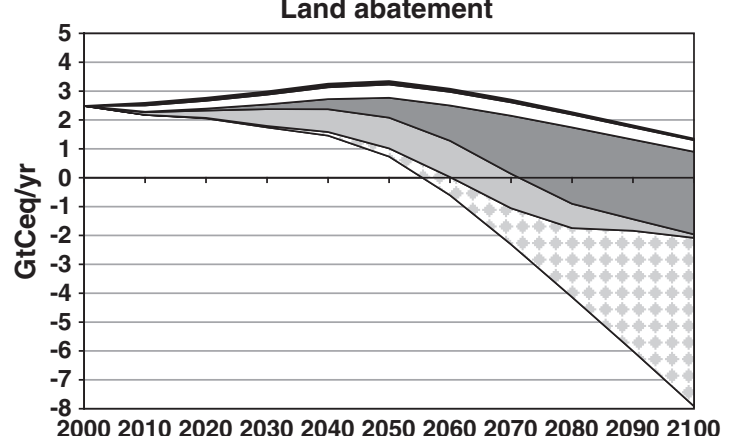

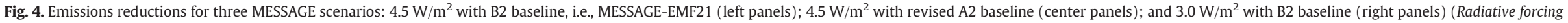
levels for 2100 for stabilization with multigas \& sinks mitigation.). 

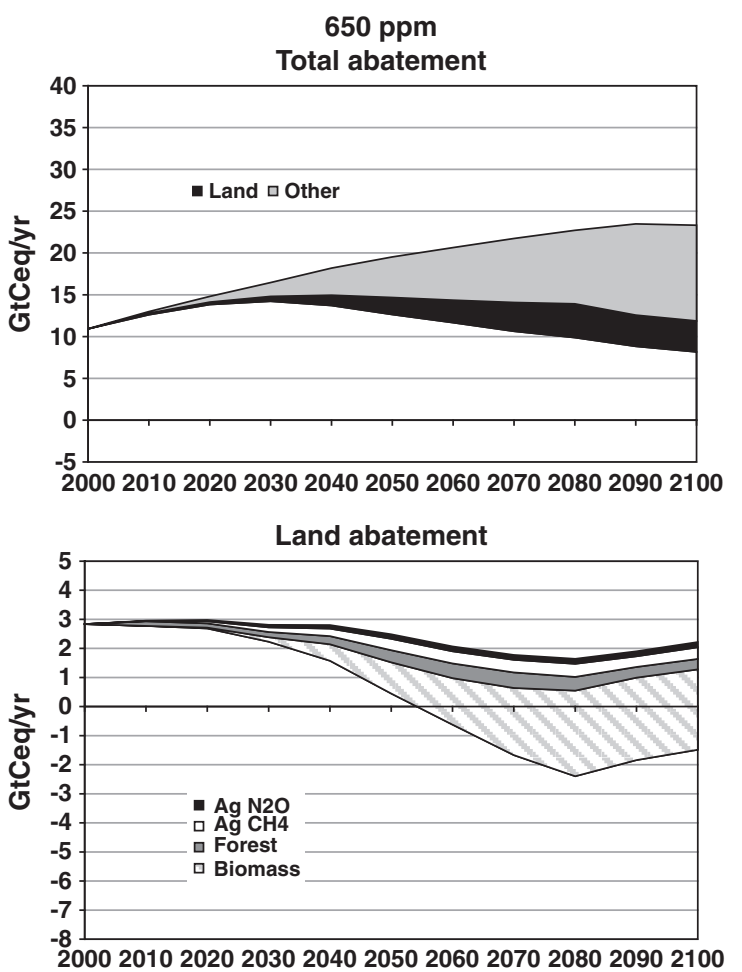

550 ppm
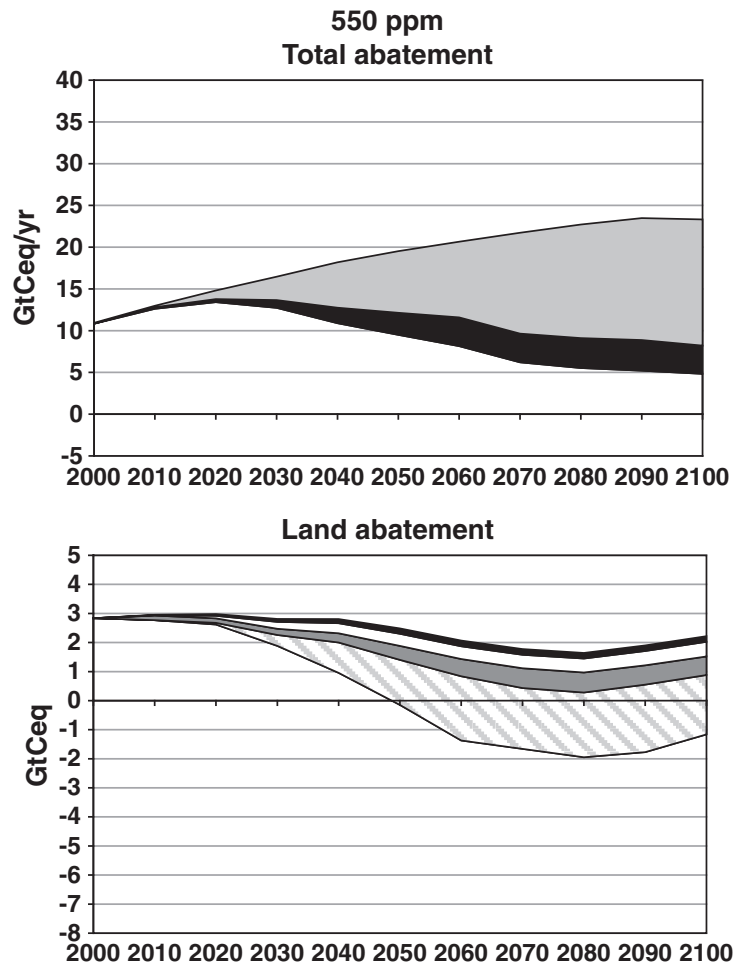

450 ppm

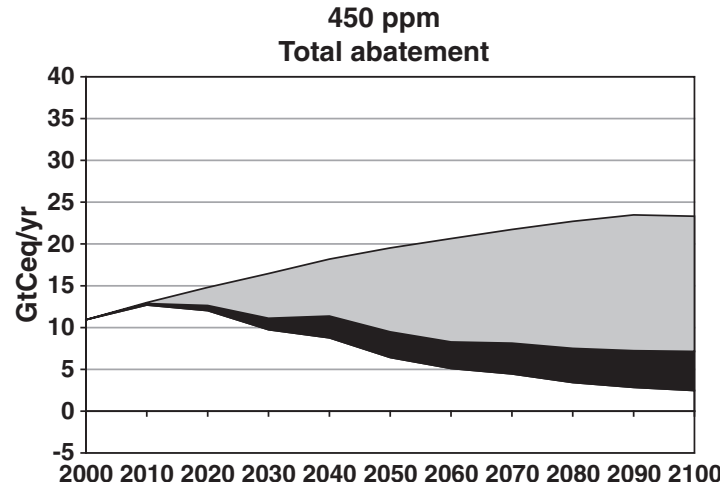

20002010202020302040205020602070208020902100

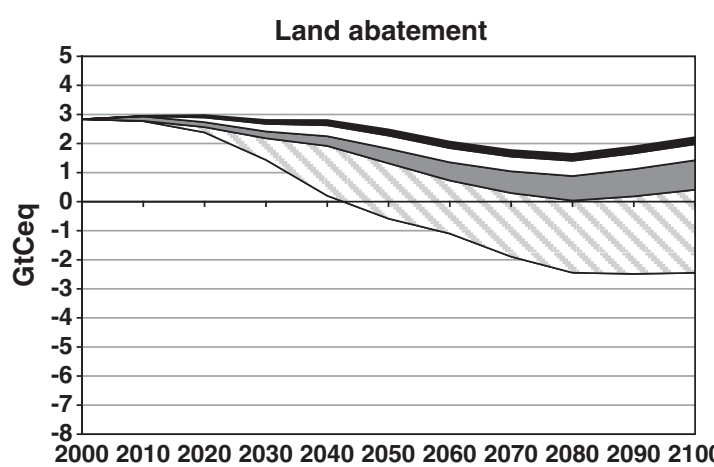

Fig. 5. Emissions reductions for three IMAGE 2.3 scenarios: stabilization with targets 650,550 , and $450 \mathrm{ppm} \mathrm{CO}_{2}$ equivalent concentrations in $2100\left(\sim 4.5,3.7,2.9 \mathrm{~W} / \mathrm{m}^{2}\right)$ with multigas and sinks mitigation. 
(a)

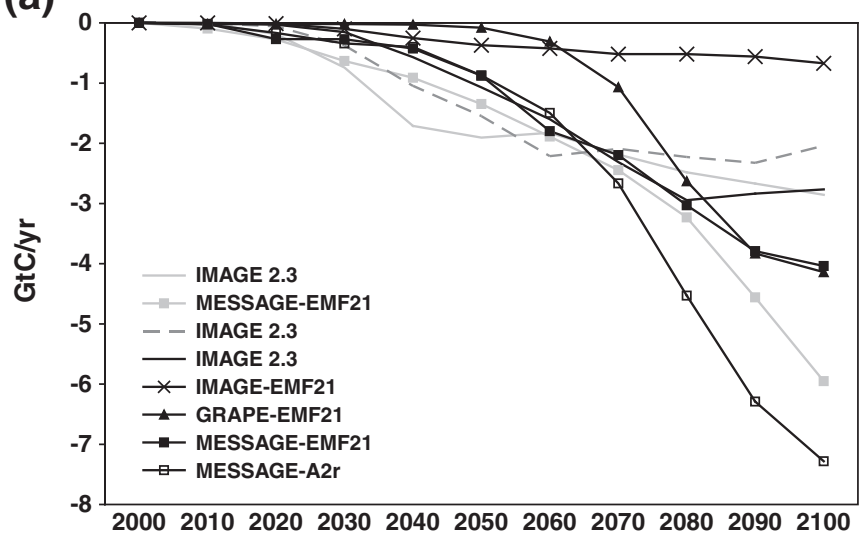

(b)

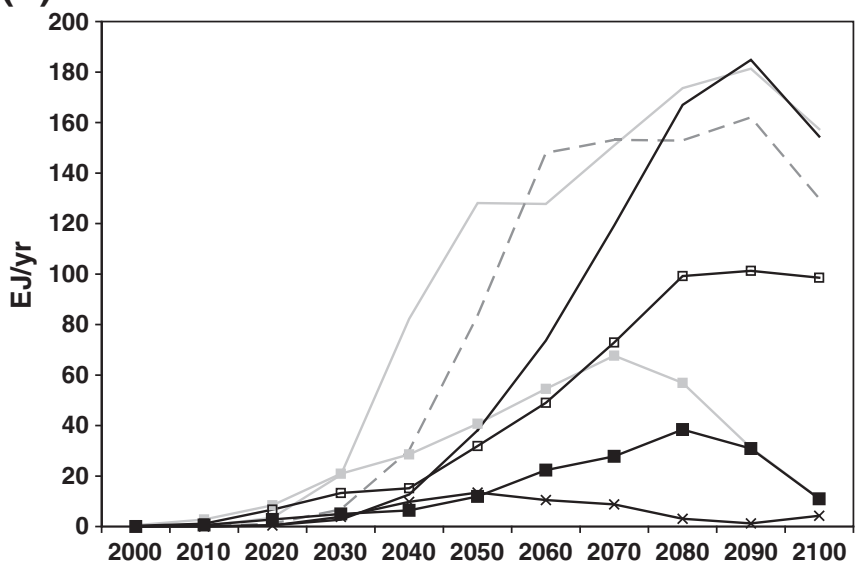

Notes: The color of the line indicates the 2100 stabilization target modeled: grey $<3.25 \mathrm{~W} / \mathrm{m}^{2}\left(<420 \mathrm{CO}_{2}\right.$ concentration, $<510 \mathrm{CO}_{2}$ eq concentration), grey dashed 3.25- 4 (420-490, 510-590), and black $4-5$ $(490-570,590-710)$. The IMAGE-EMF21 and IMAGE 2.3 forest results are net of deforestation carbon loses induced by bioenergy crop extensification. These carbon loses are accounted for under forestry by the other scenarios. Biomass primary energy data for GRAPE was not available.

Fig. 6. Biomass mitigation associated with various 2100 stabilization targets-(a) Annual GHG emissions mitigated (GtC/yr), (b) Annual biomass primary energy above baseline (EJ/yr).

Demands for bioenergy in the GRAPE, MESSAGE, and IMAGE 2.3 models include both solid and liquid feedstocks for electric power and end use sectors (transportation, buildings, industry, and non energy uses). Fig. $6 \mathrm{~b}$ presents the amount of commercial biomass primary energy utilized in the various IMAGE and MESSAGE stabilization scenarios. For example, in 2050, bio-energy could provide 12 to $38 \mathrm{EJ}$ of energy above the baseline for stabilization around $4.5 \mathrm{~W} / \mathrm{m}^{2}$ and 30 to $128 \mathrm{EJ}$ for targets less than $3.25 \mathrm{~W} / \mathrm{m}^{2}$. The IMAGE results for these target ranges ( 13 to 38 and $128 \mathrm{EJ}$ ) represent 2 to 5 and $20 \%$ of total primary energy in 2050 respectively. Over the century and across the scenarios, additional bio-energy associated with mitigation could cost-effectively provide 0.5 to $9.5 \mathrm{ZJ}$ of energy-as much as $15 \%$ of total primary energy. ${ }^{18}$

The cost-effective portfolio over time of the bio-energy alternatives is similar in the IMAGE 2.3 and MESSAGE scenarios. When BECS is not available as a mitigation strategy, electric power is projected to dominate bio-energy demand in the initial decades and, in general, with less stringent stabilization targets. Later in the decade and for more stringent targets, transportation is projected to dominate bioenergy use. With BECS available, bio-energy mitigation shifts to the

\footnotetext{
18 Calvin et al. (2009) offer a point of comparison. They use approximately $140 \mathrm{EJ} /$ year of bioenergy in 2050 in scenarios that target $2.6 \mathrm{~W} / \mathrm{m}^{2}$ in 2100 with global participation in abatement starting in 2010. Total bioenergy rises to 180-200 EJ/year in 2095, with BECS a key technology, and even more so in overshoot and staggered participation scenarios.
}

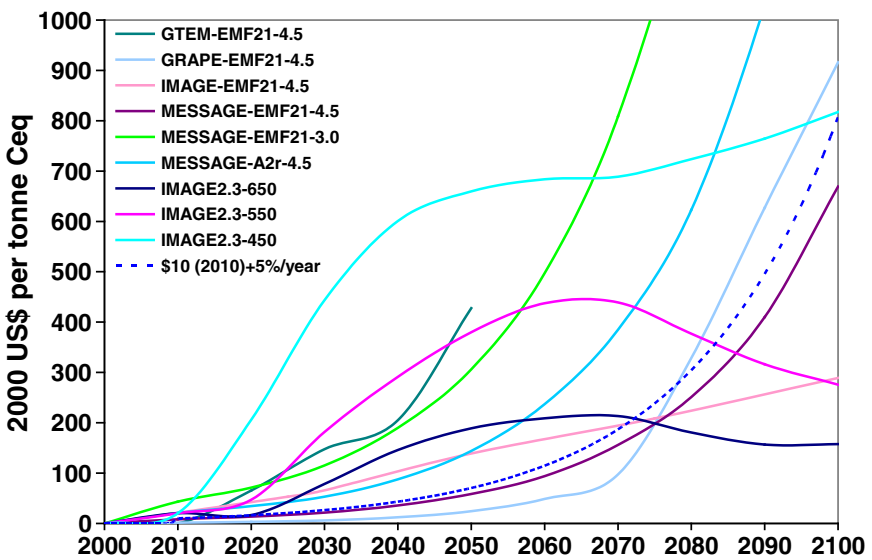

Fig. 7. GHG price paths (stabilization denoted with solid lines, hypothetical denoted by the dashed line).

power sector to take advantage of the net negative emissions from the combined abatement option. The viability of the $\mathrm{CO}_{2}$ capture and storage technology is typically assumed to increase over the century, which explains the rapid growth in BECS. It also explains the shift away from non-electricity bio-energy late in the century, which occurs earlier with a tighter stabilization target or greater baseline emissions (e.g., Fig. 4).

\section{Comparing stabilization forestry results to sectoral modeling scenarios}

In addition to the integrated assessment and climate economic models there are sectoral economic land models, especially global forestry models. Many of the integrated assessment and climate economic models currently use the sectoral models for modeling land sector emissions and mitigation activities and costs. Generally, the integrated assessment and climate economic models either implement mitigation response curves generated by the sectoral model (e.g., Jakeman and Fisher, 2006), iterate with a land sector model (e.g., Rao and Riahi, 2006; Sands and Leimbach, 2003), or calibrate model responses to sectoral modeling results (Hertel et al., 2009a). Therefore, it is natural to ask what long term mitigation do the sectoral land economic models independently project? The sectoral models use exogenous GHG price paths to simulate different climate policies and assumptions (e.g., Sohngen and Sedjo, 2006). ${ }^{19}$ Therefore, we can search for similar inferred GHG price paths in the stabilization scenarios and compare results. In Fig. 7 we have plotted the GHG price paths inferred from many of the stabilization scenarios discussed above (solid lines). These are the inferred (shadow) carbon equivalent price trajectories associated with stabilization at the specified target. Fig. 7 also plots one of the GHG price paths analyzed by two recent global forestry sectoral mitigation studies $-\$ 10 / \mathrm{tC}$ starting in 2010 that rises 5\% per year (dashed line; Sathaye et al., 2006; Sohngen and Sedjo, 2006). The stabilization results show that, in general, rising GHG prices are consistent with the cost-effective pathways. $^{20}$

\footnotetext{
19 The starting point of the GHG price path and rate of increase represent the aggressiveness of the abatement policy, abatement option and cost assumptions, and the social discount rate.

20 The exceptions in Fig. 7 are from IMAGE 2.3 scenarios that had specific features: requirement to follow a particular emissions pathway over the century, versus only requiring a 2100 target; future technology development that results in lower mitigation costs over time; and, a restriction on the amount of overshoot allowed of the long-run target. The results are carbon price paths that rise quickly during the first half of the century and much more slowly in the second half.
} 
Table 3

Cumulative forest carbon gained above baseline from long-term global forestry and stabilization scenarios (GtC).

\begin{tabular}{lllrr}
\hline & & 2020 & 2050 & 2100 \\
\hline \$10 (2010) +5\% per year & & & & \\
Sathaye et al. (2006) & World & na & 24.9 & 96.5 \\
& Temperate & na & 6.9 & 32.4 \\
Sohngen and Sedjo (2006) & Tropics & na & 15.0 & 66.0 \\
original baseline & World & 0.0 & 6.2 & 146.6 \\
& Temperate & 0.9 & 2.2 & 56.7 \\
Sohngen and Sedjo (2006) & Tropics & -0.9 & 4.0 & 89.9 \\
accelerated deforestation baseline & World & 0.4 & 4.1 & 132.9 \\
& Temperate & 0.3 & 3.3 & 58.0 \\
& Tropics & 0.2 & 0.8 & 75.0 \\
Stabilization at 4.5 W/m ${ }^{2}$ by 2100 & & & & \\
GRAPE-EMF21 & & & & \\
& World & -0.2 & 19.2 & 79.6 \\
MESSAGE-EMF21 & Temperate & 0.0 & 2.7 & 12.3 \\
& Tropics & -0.1 & 16.5 & 67.3 \\
& World & 0.0 & 0.9 & 41.6 \\
IMAGE-EMF21 & Temperate & 0.0 & 0.0 & 6.4 \\
additional sinks uptake only & Tropics & 0.0 & 0.9 & 35.2 \\
IMAGE-EMF21 & World & 2.4 & 11.3 & 31.1 \\
change in net forest carbon stock & Temperate & 2.1 & 9.1 & 24.8 \\
& Tropics & 0.3 & 2.2 & 6.3 \\
& World & -6.1 & -3.7 & 2.8 \\
& Temperate & 3.9 & 8.7 & 21.4 \\
& Tropics & -10.0 & -12.4 & -18.5 \\
\hline & & & &
\end{tabular}

Notes:

Tropics: Central America, South America, Sub-Saharan Africa, South Asia, Southeast Asia.

Temperate: North America, Western and Central Europe, Former Soviet Union, East Asia, Oceania, Japan.

na $=$ data not available

a Results based on the $4.5 \mathrm{~W} / \mathrm{m}^{2}$ MESSAGE scenario from the sensitivity analysis of Rao and Riahi (2006) that used the DIMA forestry model.

Table 3 compares the forest mitigation outcomes from stabilization scenarios that have a GHG price trajectory similar to the $\$ 10 / \mathrm{tC}$ in $2010+5 \% / y r$ used by Sohngen and Sedjo and Sathaye et al. Two sets of IMAGE results are presented in Table 3. The first represents the carbon gains from the planting of additional forest plantations in the cost-effective portfolio. The second represents the net changes in the forest carbon stock from multiple forces, including additional plantations, changes in $\mathrm{CO}_{2}$ fertilization forest growth responses, and bio-energy induced deforestation. The former is more directly comparable to the other scenarios in Table 3. These IMAGE results and the results from the other models are discussed in the next few paragraphs. The IMAGE net forest carbon stock change results are discussed further below.

Rising GHG prices will provide incentives for additional forest area, longer rotations, and more intensive management to increase carbon storage. Consistent with our previous discussion, Table 3 shows that the vast majority of forest mitigation is projected to occur in the second half of the century. Table 3 also shows that tropical regions in most cases assume a larger share of global forest sequestration mitigation than temperate regions. Sohngen and Sedjo and Sathaye et al. project that tropical forest mitigation activities are expected to be heavily dominated by land use change activities (reduced deforestation and afforestation), while land management activities (increasing inputs, changing rotation length, adjusting age or species composition) are expected to be slightly more than half of the mitigation in temperate regions. The current stabilization scenarios include more limited and aggregated forestry GHG abatement technologies that do not distinguish the detailed responses seen in the sectoral models.

The sectoral models, in particular, Sohngen and Sedjo, suggest substantially more mitigation than the integrated assessment models in the second half of the century. A number of factors contribute to this deviation from the integrated assessment model results. First and foremost, Sohngen and Sedjo account for expected changes in future timber and GHG prices, which none of the integrated assessment models are currently capable of doing (they instead implicitly assume that current and future prices are the same). Therefore, a low GHG price that is expected to increase rapidly in the future results in a postponement of additional sequestration actions in Sohngen and Sedjo until the price (benefit) of sequestration is greater. Endogenously modeling the future forest biophysical and economic implications in current decisions will be a significant future challenge for integrated assessment models. Conversely, the integrated assessment models may be producing a somewhat more muted forest sequestration response given the following: (i) their explicit consideration of cost competitive mitigation alternatives in other sectors and across regions, and, in some cases, in land use (e.g., bio-energy); (ii) their more limited set of forest related abatement options, with all integrated assessment models modeling afforestation strategies, but only some considering avoided deforestation, and none modeling forest management options at this point (Table 1); (iii) sequential land allocation rules employed by some integrated assessment models (including those in Table 3), that satisfy food and livestock feed demand growth requirements first, and (iv) climate feedbacks in integrated assessment models that can lead to terrestrial carbon loses relative to the baseline. ${ }^{21}$

The IMAGE net forest carbon stock change results in Table 3 provide a dramatic illustration of the potential implications and importance of counterbalancing effects. Despite the planting of additional forest plantations in the IMAGE scenario, net tropical forest carbon stocks decline relative to the baseline due to deforestation induced by expansion of bioenergy crops, as well as reduced $\mathrm{CO}_{2}$ fertilization effects that affect forest carbon uptake, especially tropical forests, and decrease crop productivity, where the later effect induces greater expansion of food crops onto fallow lands; thereby, displacing stored carbon. Future modeling will want to explore these biophysical and economic interactions and their implications for land-based mitigation.

\section{Conclusion and research opportunities}

This paper sheds light on and assesses an unexplored area of climate stabilization scenarios-the role of land-based mitigation technologies. This paper extracts and evaluates unpublished land modeling and GHG mitigation details from recent climate stabilization studies in order to understand and assess the role of land in long-term climate stabilization-the goal being to inform readers on a complex and relatively immature area of global model development. Overall, the paper characterizes current capabilities and limitations, discusses differences in modeling and results and robust conclusions, and identifies key uncertainties and opportunities for future land modeling development. Model comparison has proven to be a valuable instrument in energy modeling for better understanding differences in results, weighing the robustness and uncertainty of policy insights, and identifying priority areas for model improvement. Given the complexities of modeling global land use, and the early stages of its development, model comparison can be particularly useful in providing a basis for future development and subsequent comparisons.

We found that land based mitigation - agriculture, forestry, and bio-energy (liquid and solid) substitutes for fossil fuels - are all a part of the cost-effective portfolio of mitigation strategies for long-term climate stabilization. In other words, they are considered to have

\footnotetext{
${ }^{21}$ Also worthy of note is that the MESSAGE-EMF21 results from Rao and Riahi (2006) limited the potential for additional forest carbon to $50 \%$ of that estimated with the DIMA model by Rokityanskiy et al. (2007). Rao and Riahi (p. 195) note that this assumption, while only indicative, is used to represent market imperfections and infrastructure barriers. The other models (sectoral and integrated assessment) do not make this kind of adjustment.
} 
lower costs than some mitigation options in non-land using sectors, such as energy, industry, and transportation.

Agriculture, forestry, and bio-energy cost-effectively contribute throughout the century with annual abatement increasing per year. Agriculture and forestry assume larger shares of annual abatement in the near term, while bio-energy, especially BECS, assumes a significant mitigation role in the second half of the century (Fig. 8). Cumulatively, agriculture is projected to account for a smaller, though potentially strategically significant, share of the total abatement required for stabilization relative to forestry and bio-energy. Bioenergy, in particular, may have a substantial abatement role and therefore a large effect on the total mitigation cost of stabilization.

We also evaluated land's mitigation role with alternative baselines and other stabilization targets. Cost-effective land related abatement increases with higher emitting baselines and more stringent stabilization targets. However, despite increased absolute abatement levels, land's share of annual and cumulative total abatement declines while the abatement share of non-land mitigation activities increases.

Overall, current modeling suggests that land-based mitigation options offers significant potential and could help reduce the cost of stabilization. However, substantial fossil fuel emissions reductions will still be required for stabilization at the stabilization levels considered here. Land-based bio-energy could be an important fossil fuel substitution technology, and the combination of bio-energy and $\mathrm{CO}_{2}$ capture and storage might even be essential for very low stabilization scenarios. There are, however, still significant questions about the implications of large scale commercial bio-energy and the regulatory acceptability of $\mathrm{CO}_{2}$ capture and storage.

Our comparison of results from the different integrated assessment models also strongly emphasizes that there are substantial uncertainties. There is little agreement about the magnitudes of abatement. Across all the stabilization scenarios considered, land contributes around 100 to 340 GtCeq cumulatively across the century (approximately 15 to $40 \%$ of total abatement), 10 to $37 \mathrm{GtCeq}$ of abatement from agricultural methane sources, 7 to $20 \mathrm{GtCeq}$ from agricultural nitrous oxide sources, 31 to $113 \mathrm{GtCeq}$ from forestry, and 31 to $204 \mathrm{GtCeq}$ from bio-energy. The large ranges in part reflect the developing state-of-the-art for estimating the role of land-use related abatement options and the overall role of land in stabilization, compared to the more mature state of analyses of energy-related technologies. More systematic model comparisons are needed to generate an even better understanding of differences, and, possibly, to reduce the uncertainty ranges.

Across the six $4.5 \mathrm{~W} / \mathrm{m}^{2} 2100$ radiative forcing stabilization scenarios, land as a whole contributed cumulative abatement of

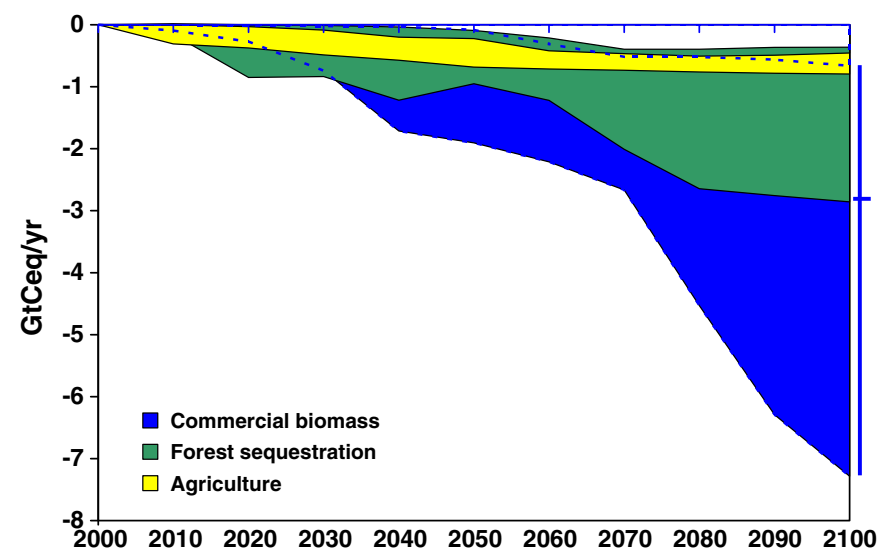

Fig. 8. Annual abatement ranges for commercial biomass, forestry, and agriculture across the stabilization studies considered. approximately 20 to 45 GtCeq by 2050 ( 15 to $70 \%$ of total abatement) and approximately 95 to $310 \mathrm{GtCeq}$ by 2100 (15 to 45\%). The magnitude and timing of the individual types of land related mitigation for $4.5 \mathrm{~W} / \mathrm{m}^{2}$ stabilization vary across scenarios, with agricultural $\mathrm{CH}_{4}$ emissions reductions of 0.1 to 9.9 and 9.6 to 32.8 GtCeq by 2050 and 2100 respectively, agricultural $\mathrm{N}_{2} \mathrm{O}$ emissions reductions of 1.6 to 10.8 and 70 to $19.9 \mathrm{GtCeq}$, additional forest sequestration above the baseline of 0.9 to 27.1 and 31.2 to $79.6 \mathrm{GtC}$, and bio-energy emissions offsets and sequestration of 1.3 to 14.2 and 30.9 to $204.3 \mathrm{GtC}$ respectively.

The broad ranges are a reflection of the state of the art (data and modeling), which is still young and evolving. Below we identify some key opportunities for development.

\subsection{Research opportunities}

To date, most global integrated assessment and climate economic models have entertained exogenous or partial model linking approaches to incorporate land-based mitigation costs. Endogenizing land-based mitigation within a model requires that land input use and competition be explicitly modeled (discussed more below). Individually, forestry, agriculture, and bio-energy present unique challenges for endogenizing the cost of land mitigation. While forestry mitigation strategies are not novel, modeling forest investment behavior calls for dynamic optimization modeling with endogenous future markets, versus recursive modeling. ${ }^{22}$ Econometric modeling of dynamic land allocation and land management decisions (e.g., Lubowski et al., 2006; Plantinga et al., 1999; Stavins, 1999) provides useful information for calibrating dynamic optimization responses of forward-looking agents, and could also provide an intermediate approach that could be more immediately applied in other dynamic programming frameworks. For agriculture, modeling of the detailed mitigation actions and technologies represented in agricultural abatement schedules requires more precise modeling of agricultural emissions sources and drivers; and, use of techniques for endogenizing costs like those employed for modeling non- $\mathrm{CO}_{2}$ GHG mitigation for the energy and industry sectors (Hyman et al., 2003) and more refined techniques that allow for input substitution away from emissions intensive inputs (Golub et al., 2009; Hertel et al., 2009a). Finally, bioenergy production is a relatively new economic sector that lacks historical data, which complicates model calibration.

Refinement of the estimates of bio-energy abatement potential should be a priority model development agenda item. Research is needed to improve the characterization of bio-energy's potential, including the opportunity costs of land and utilization alternatives, processing constraints, geologic formation characterization, fertilizer use implications, and ecosystem externalities. In particular, present studies are relatively poor in representing land competition with food supply and timber production, which has a significant influence on the economic potential of bioenergy crops. Recent studies have raised concerns about potential domestic biofuels programs that could stimulate international land-use changes and result in a net increase in global greenhouse gas emissions (e.g., Fargione et al., 2008; Searchinger et al., 2008), although it may be possible to reduce these indirect impacts. Similar concerns are relevant for some forms of large-scale bio-electricity deployment (with and without carbon dioxide capture and storage). However, current studies have limitations in their inability to estimate changes in land-use in response to the policy. This issue, in particular, places a premium on explicit modeling of land-use behavior and land markets that capture the opportunity cost of land-use and land management decisions, as well as demand responses to rising prices.

\footnotetext{
${ }^{22}$ For global sectoral modeling examples, see Sohngen and Sedjo (2006) and Sathaye et al. (2006), who use different approaches in considering future timber prices.
} 
There are also policy concerns about the permanence of terrestrial carbon stocks. Terrestrial carbon stocks can be released to the atmosphere by natural disturbance or land owners pursuing alternative rents. Economic models capture the former in allowing for forest harvests if profitable given the net of timber benefits and the value of the carbon released (net wood products). Changes in disturbance regimes however are not currently reflected. The models assume the continuation of historic disturbance regimes. This modeling also assumes specific base year terrestrial carbon stocks and fluxes. There is, of course, uncertainty about both these elements. Alternative representations would affect results. For instance, higher baseline deforestation emissions imply a higher cost for avoiding deforestation (e.g., Sohngen and Sedjo, 2006).

Long-run land climate modeling is rapidly evolving and many of these modeling challenges are starting to be addressed by on-going model development. Recent developments in data and modeling techniques should be helpful (Bouwman et al., 2006; Hertel et al., 2009b). A central development initiative is the improvement in the dynamic modeling of regional and sub-regional land-use and land-use competition (e.g., Hertel et al., 2009b). The total cost of any landbased mitigation strategy should include the opportunity costs of land, which are dynamic and regionally unique functions of changing regional bio-physical and economic circumstances. An essential part of improved land competition modeling is endogenous modeling of forest biophysical and economic dynamics. Better modeling of competition between land-uses will improve leakage estimates and help identify comparative advantages in land-related mitigation and production.

Other important issues include long-run interactions between mitigation and potential climate change impacts (e.g., fires, pests, weeds, atmospheric $\mathrm{CO}_{2}$ fertilization, precipitation and water availability), evaluation of key baseline input sensitivities and narrowing the range of acceptable values (e.g., crop productivity in Sands and Leimbach, 2003; land supply and harvesting costs in Sohngen and Mendelsohn, 2006), and improvements in mitigation cost estimates for agriculture to address uncertainties due to the novel and detailed mitigation technologies represented and land heterogeneity, which imply data limitations and uncertainty about adoption and marginal responses. Uncertainties about the full cost of forest conversion introduce uncertainty into the opportunity cost of land and the substitution elasticity for land conversion. Recent econometric work will help bound this uncertainty (e.g., Lubowski et al., 2006). However, estimates are lacking for most global regions.

Furthermore, with more sophisticated land modeling, we will be better able to evaluate alternative policy instrument designs and project and region specific costs and risks that will affect land allocation within and across regions. For instance, program design decisions (e.g., eligible abatement activities) and delays in program implementation will affect the net value of both the eligible and ineligible activities (e.g., Rose and Sohngen, 2011). In addition, current modeling does not account for transactions costs (the legal, administrative, and financial risks associated with transacting mitigation investments). Transactions costs are likely to be incurred under any compliance program and institutional arrangement, and for all abatement options-land-based and non-land-based (energy, industry, and transportation). Unfortunately, transactions costs data is scarce. Data is needed for all mitigation activities and regions in order to have balanced global treatment in modeling.

We believe that subsequent comparison studies with experiments explicitly formulated to explore land use behavior across models would further inform the growing interest in understanding land's potential role in climate change mitigation. In particular, future analyses should pursue additional details that include, among other things, acreage requirements, energy supply and demand implications, commodity price and demand responses, trade effects, land-use intensification versus land-use extensification (expansion), and the implications for different regions. In addition, many current stabilization applications of top-down models, as well as many bottom-up analyses, make the optimistic assumption of immediate and simultaneous global adoption of a coordinated climate policy with an unconstrained, or almost unconstrained, set of mitigation options across sectors. These assumptions, ceteris paribus, bias stabilization cost estimates downward. Future analyses should include evaluation of alternative timing and constrained mitigation option sets for regional land-related abatement programs.

\section{Appendix A. Supplementary data}

Supplementary data to this article can be found online at doi:10. 1016/j.eneco.2011.06.004.

\section{References}

Beach, R.H., DeAngelo, B.J., Rose, S.K., Li, C., Salas, W., DelGrosso, S.J., 2008. Mitigation potential and costs for global agricultural greenhouse gas emissions. Agricultural Economics 38, 1-7.

Bouwman, A.F., Kram, T., Klein, G.K., 2006. Integrated Modelling of Global Environmental Change. An Overview of IMAGE 2.4. Netherlands Environmental Assessment Agency, Bilthoven. October 2006, MNP publication number 500110002/2006.

Calvin, K., Edmonds, J., Bond-Lamberty, B., Clarke, L., Kim, S.H., Kyle, P., Smith, S.J., Thomson, A., Wise, M., 2009. 2.6: Limiting climate change to $450 \mathrm{ppm} \mathrm{CO}_{2}$ equivalent in the 21st century. Energy Economics 31 (Supplemental 2), S107-S120.

Clarke, L., Edmonds, J., Krey, V., Richels, R., Rose, S., Tavoni, M., 2009. International climate policy architectures: overview of the EMF 22 international scenarios. Energy Economics 31 (Supplemental 2), S64-S81.

DeAngelo, B.J., de la Chesnaye, F.C., Beach, R.H., Sommer, A., Murray, B.C., 2006. Methane and nitrous oxide mitigation in agriculture. Energy Journal 47, 89-108 (Special Issue \#3, Multigas Mitigation and Climate Policy).

Dyson, F.J., 1977. Can we control the carbon dioxide in the atmosphere. Energy 2, 287-291.

Fargione, J., Hill, J., Tilman, D., Polasky, S., Hawthorne, P., 2008. Land clearing and the biofuel carbon debt. Science 319 (5867), 1235-1238.

Fisher, B.S., Nakicenovic, N., Alfsen, K., Corfee Morlot, J., de la Chesnaye, F., Hourcade, J.-Ch., Jiang, K., Kainuma, M., La Rovere, E., Matysek, A., Rana, A., Riahi, K., Richels, R., Rose, S., van Vuuren, D., Warren, R.,2007. Issues related to mitigation in the long term context. In: Metz, B., Davidson, O.R., Bosch, P.R., Dave, R., Meyer, L.A. (Eds.), Climate Change 2007: Mitigation. Contribution of Working Group III to the Fourth Assessment Report of the Inter-governmental Panel on Climate Change. Cambridge University Press, Cambridge, United Kingdom and New York, NY, USA.

Golub, A., Hertel, T., Lee, H.-L., Rose, S., Sohngen, B., 2009. The opportunity cost of land use and the global potential for greenhouse gas mitigation in agriculture and forestry. Resource and Energy Economics 31, 299-319.

Grübler, A., Chirkov, V., Goujon, A., Kolp, P., O'Neill, B., Prommer, I., Riahi, K., Scherbov, S., Slentoe, E., 2007. Regional, national, and spatially explicit scenarios of demographic and economic change based on SRES. Technological Forecasting and Social Change 74 (7), 980-1029 (Special Issue: Greenhouse Gases - Integrated Assessment).

Hertel, T., Lee, H.-L., Rose, S., Sohngen, B., 2009a. Modeling land-use related greenhouse gas sources and sinks and their mitigation potential. In: Hertel, T. Rose, S., Tol, T. (Eds.), Economic Analysis of Land Use in Global Climate Change Policy. Routledge Publishing.

Hertel, T., Rose, S., Tol, R. (Eds.), 2009b. Economic Analysis of Land Use in Global Climate Change Policy. Routledge Publishing.

Hoogwijk, M., Faaij, A., Eickhout, B., de Vries, B., Turkenburg, W., 2005. Potential of biomass energy out to 2100 , for four IPCC SRES land-use scenarios. Biomass and Bioenergy 29 (4), 225-257.

Houghton, R.A., 2003. Revised estimates of the annual net flux of carbon to the atmosphere from changes in land use and land management 1850-2000. Tellus 55b, 378-390.

Houghton, R.A., 2008. Carbon flux to the atmosphere from land-use changes: 18502005. TRENDS: A Compendium of Data on Global Change. Carbon Dioxide Information Analysis Center, Oak Ridge National Laboratory, U.S. Department of Energy, Oak Ridge, Tenn., U.S.A. http://cdiac.ornl.gov/trends/landuse/houghton/ houghton.html.

Hyman, R.C., Reilly, J.M., Babiker, M.H., De Masin, A., Jacoby, H.D., 2003. Modeling non$\mathrm{CO}_{2}$ greenhouse gas abatement. Environmental Modeling and Assessment 8, $175-186$.

IPCC (Intergovernmental Panel on Climate Change), 1995. Climate change 1995: impacts, adaptations and mitigation of climate change: scientific-technical analyses. Contribution of Working Group II to the Second Assessment of the IPCC. Cambridge University Press, Cambridge.

IPCC (Intergovernmental Panel on Climate Change), 2000. Land use, land-use change, and forestry. A Special Report of the IPCC. Cambridge University Press, Cambridge. $377 \mathrm{pp}$.

IPCC (Intergovernmental Panel on Climate Change), 2001. Climate change 2001: mitigation. Contribution of Working Group III to the Third Assessment Report of the IPCC. Cambridge University Press, Cambridge. 752 pp. 
IPCC (Intergovernmental Panel on Climate Change), 2007. Climate change 2007 mitigation of climate change. Contribution of Working Group III to the Fourth Assessment Report of the IPCC. Cambridge University Press, Cambridge. 851 pp.

Jakeman, G., Fisher, B.S., 2006. Benefits of multi-gas mitigation: an application of the Global Trade and Environment Model (GTEM). Energy Journal 47, 323-342 (Special Issue \#3, Multigas Mitigation and Climate Policy).

Kurosawa, A., 2006. Multigas mitigation: an economic analysis using GRAPE model. Energy Journal 47, 275-288 (Special Issue \#3, Multigas Mitigation and Climate Policy).

Lashof, D., Tirpak, D., 1989. Policy options for stabilizing global climate. Report to Congress. Volume II. United States Environmental Protection Agency, Washington, D.C.

Lubowski, R.N., Plantinga, A.J., Stavins, R.N., 2006. Land-use change and carbon sinks: econometric estimation of the carbon sequestration supply function. Journal of Environmental Economics and Management 51 (2), 135-152.

Marland, G., 1988. The prospects of solving the $\mathrm{CO}_{2}$ problem through global reforestation. U.S. Department of Energy DOE/NBB-0082. .

McGuire, A.D., Sitch, S., Clein, J.S., Dargaville, R., Esser, G., Foley, J., Heimann, M., Joos, F., Kaplan, J., Kicklighter, D.W., Meier, R.A., Melillo, J.M., Moore III, B., Prentice, I.C. Ramakutty, N., Reichenau, T., Schloss, A., Tian, H., Williams, L.J., Wittenberg, U., 2001. Carbon balance of the terrestrial biosphere in the twentieth century: analyses of $\mathrm{CO}_{2}$, climate and land use effects with four process-based ecosystem models. Global Biogeochemical Cycles 15 (1), 183-206.

Olivier, J.G.J., 2002. Part III: Greenhouse gas emissions: 1. Shares and trends in greenhouse gas emissions; 2 . Sources and methods; greenhouse gas emissions for 1990 and 1995, CO 2 emissions from fuel combustion 1971-2000, 2002 Edition. International Energy Agency (IEA), Paris. ISBN: 92-64-09794-5, pp. III.1-III.31.

Plantinga, A.J., Mauldin, T., Miller, D.J., 1999. An econometric analysis of the costs of sequestering carbon in forests. American Journal of Agricultural Economics 81, 812-824.

Rao, S., Riahi, K., 2006. The role of non- $\mathrm{CO}_{2}$ greenhouse gases in climate change mitigation: long-term scenarios for the 21 st century. Energy Journal 47, 177-200 (Special Issue \#3, Multigas Mitigation and Climate Policy).

Riahi, K., Gruebler, A., Nakicenovic, N., 2007. Scenarios of long-term socio-economic and environmental development under climate stabilization. Technological Forecasting and Social Change 74 (7), 887-935 (Special Issue: Greenhouse Gases - Integrated Assessment).

Rokityanskiy, D., Benitez, P., Kraxner, F., McCallum, I., Obersteiner, M., Rametsteiner, E., Yamagata, Y., 2007. Geographically explicit global modeling of land-use change, carbon sequestration and biomass supply. Technological Forecasting and Social Change 74 (7), 1057-1082 (Special Issue: Greenhouse Gases - Integrated Assessment).

Rose, S., Sohngen, B., 2011. Global forest carbon sequestration and climate policy design. Environment and Development Economics. Available on CJO 2011 doi:10.1017/S1355770X11000027, pp 26.

Rose, S., Lee, H.-L., 2009. Non-CO2 greenhouse gas emissions data for climate change economic analysis. In: Hertel, T.W., Rose, S.K., Tol, R. (Eds.), Routledge Publishing, pp. 348.

Rose, S., Ahammad, H., Eickhout, B., Fisher, B., Kurosawa, A., Rao, S., Riahi, K., van Vuuren, D., 2008. Land in climate stabilization modeling: initial observations. EMF
Report Number 21, Energy Modeling Forum, Stanford University, July. http://www. stanford.edu/group/EMF/home/index.htm.

Sands, R.D., Leimbach, M., 2003. Modeling agriculture and land use in and integrated assessment framework. Climatic Change 56, 185-210.

Sathaye, J., Makundi, W., Dale, L., Chan, P., Andrasko, K., 2006. GHG mitigation potential, costs and benefits in global forests: a dynamic partial equilibrium approach. Energy Journal 47, 127-162 (Special Issue \#3, Multigas Mitigation and Climate Policy).

Searchinger, T., Heimlich, R., Houghton, R.A., Dong, F., Elobeid, A., Fabiosa, J., Tokgoz, S. Hayes, D., Yu, T.-H., 2008. Use of U.S. croplands for biofuels increases greenhouse gases through emissions from land-use change. Science 319 (5867), 1238-1240.

Sohngen, B., Mendelsohn, R., 2003. An optimal control model of forest carbon sequestration. American Journal of Agricultural Economics 85 (2), 448-457.

Sohngen, B., Mendelsohn, R., 2006. A sensitivity analysis of carbon sequestration. In: Schlesinger, M. (Ed.), Human-Induced Climate Change: An Interdisciplinary Assessment. Cambridge University Press, Cambridge.

Sohngen, B., Sedjo, R., 2006. Carbon sequestration in global forests under different carbon price regimes. Energy Journal 47, 109-126 (Special Issue \#3, Multigas Mitigation and Climate Policy).

Stavins, R.N., 1999. The costs of carbon sequestration: a revealed-preference approach. The American Economic Review 89 (4), 994-1009.

Strengers, B.J., van Minnen, J.G., Eickhout, B., 2008. The role of carbon plantations in mitigating climate change: potentials and costs. Climatic Change 88 (3-4), 343-366.

USEPA (U.S. Environmental Protection Agency), 2005. Greenhouse gas mitigation potential in U.S. forestry and agriculture. EPA Report EPA-R-05-006. U.S Environmental Protection Agency, Office of Atmospheric Programs, Washington, D.C.

USEPA (U.S. Environmental Protection Agency), 2006a. Global anthropogenic emissions of non- $\mathrm{CO}_{2}$ greenhouse gases 1990-2020. EPA Report 430-R-06-003. United States Environmental Protection Agency, Washington, DC. http://www.epa.gov/nonco2/ econ-inv/international.html.

USEPA (U.S. Environmental Protection Agency), 2006b. Global mitigation of non- $\mathrm{CO}_{2}$ greenhouse gases. EPA Report 430-R-06-005. United States Environmental Protection Agency, Washington, DC. http://www.epa.gov/nonco2/econ-inv/ international.html.

van Vuuren, D.P., Eickhout, B., Lucas, P.L., den Elzen, M.G.J., 2006a. Long-term multi-gas scenarios to stabilise radiative forcing: exploring costs and benefits within an integrated assessment framework. Energy Journal 47, 201-234 (Special Issue \#3. Multigas Mitigation and Climate Policy).

van Vuuren, D.P., Weyant, J., de la Chesnaye, F., 2006b. Multigas scenarios to stabilise radiative forcing. Energy Economics 28, 102-120.

van Vuuren, D.P., den Elzen, M.G.J., Lucas, P.L., Eickhout, B., Strengers, B.J., van Ruijven, B., Wonink, S., van Houdt, R., 2007. Stabilizing greenhouse gas concentrations at low levels: an assessment of reduction strategies and costs. Climatic Change 81 (2), 119-159.

Vitousek, P.M., Mooney, H.A., Lubchenco, J., Melillo, J.M., 1997. Human domination of Earth's ecosystems. Science 277 (5325), 494-499.

Weyant, J.P., de la Chesnaye, F., Blanford, G., 2006. Overview of EMF-21. Energy Journal 47, 1-32 (Special Issue \#3, Multigas Mitigation and Climate Policy). 